\title{
Article
}

\section{Dynamics of Processes with Recycle: Multifeed Ternary Systems}

Chia-Tsung Hung, Yih-Hang Chen, Jeffrey D. Ward, and Cheng-Ching Yu

Ind. Eng. Chem. Res., 2006, 45 (25), 8664-8677 • DOI: 10.1021/ie051449+

Downloaded from http://pubs.acs.org on November 28, 2008

\section{More About This Article}

Additional resources and features associated with this article are available within the HTML version:

- $\quad$ Supporting Information

- Access to high resolution figures

- $\quad$ Links to articles and content related to this article

- $\quad$ Copyright permission to reproduce figures and/or text from this article

\section{View the Full Text HTML}




\title{
Dynamics of Processes with Recycle: Multifeed Ternary Systems
}

\author{
Chia-Tsung Hung, ${ }^{\dagger}$ Yih-Hang Chen, ${ }^{\ddagger}$ Jeffrey D. Ward, ${ }^{\dagger}$ and Cheng-Ching Yu ${ }^{*, \dagger}$ \\ Department of Chemical Engineering, National Taiwan University, Taipei 106-07, Taiwan, and Department of \\ Energy and Resources Laboratory, Industrial Technology Research Institute, Hsinchu 310, Taiwan
}

\begin{abstract}
We explore the dynamics and control of plants with recycle and multiple feed streams under different process designs, taking as an example a ternary system with a second-order irreversible reaction: $\mathrm{A}+\mathrm{B} \rightarrow 2 \mathrm{C}$. Process transfer function matrices are derived analytically in terms of design variables. It is shown analytically that plants with recycle and multiple feeds are internally unstable systems with a pole at the origin, thus proving Luyben's conjecture that reactant feed flow rates must be balanced down to the last molecule. Therefore, a feed-ratio control scheme will not work in practice; one of the feed flows must be adjusted via feedback. Remaining candidate control structures are evaluated using linear and nonlinear analysis. Finally, dynamic compensation of the feed flow is applied such that almost perfect production rate control is achieved. Simulation results clearly indicate that the correct control structure can be selected and that almost perfect production rate changes can be achieved.
\end{abstract}

\section{Introduction}

Because of stringent environmental regulations and economic considerations, modern chemical plants tend to be highly integrated and interconnected. The steady-state and dynamic behaviors of these interconnected plants differ significantly from those of their individual components. ${ }^{1-6}$ A typical plant configuration consists of reactor/separator processes with material recycle, where unreacted reactants are recycled back to the reactor. ${ }^{6-9}$ Dynamics and control of processes with recycle streams have received little attention until recently. A pioneering work by Gilliland et al. ${ }^{10}$ explained the dynamics of a reactor/ separator system. They pointed out that the effect of the recycle stream is to increase the time constants of the process. Verykios and Luyben ${ }^{11}$ studied a slightly more complex process with simplified column dynamics and showed that such recycling systems can exhibit underdamped behavior. Denn and Lavie ${ }^{1}$ also showed that the response time of recycle systems can be substantially longer than the response time of individual units. Taiwo ${ }^{12}$ discussed the robust control of plants with recycle, and Zheng and Mahajanam ${ }^{13}$ proposed a controllability measure for recycling plants. Chodavarapu and Zheng ${ }^{14}$ develop heuristics for tuning feedback controllers for processes with recycle based on qualitative information about the dynamics of the processes inside and outside the recycle loop. In a series of articles, Luyben ${ }^{2,3,15}$ investigated the effects of recycle loops on process dynamics and their implications for plantwide control. Taiwo ${ }^{12}$ pioneered the use of a recycling compensator to restore inherent process dynamics (dynamics without recycling), the same method later employed by Scali and Ferrari. ${ }^{5}$ Lakshminarayanan and Takada $^{16}$ discuss system identification for the design of recycle compensators, and Kwok et al. ${ }^{17}$ compare recycle compensators with feedback controllers designed using Tayor series and seasonal time series.

It is well-known that, topologically, material recycle in an interconnected process is equivalent to a positive feedback system with a loop gain of less than unity. In a typical positive

* Corresponding author. Fax: +886-2-2362-3040. E-mail: ccyu@ ntu.edu.tw.

† National Taiwan University.

$\doteqdot$ Industrial Technology Research Institute. feedback configuration, if the loop gain is increased, two phenomena are observed: (1) the process dynamics slow and (2) the steady-state gain in the direct path increases. ${ }^{1,2,4,5,18}$ However, a reactor/separator process may behave very differently. A smaller recycle flow corresponds to a higher reactor conversion and, thus, slower reactor dynamics. Issues such as how these competing effects affect the dynamics of the positive feedback system and the implications of these effects for control structure design need to be studied.

Nonlinear analysis (including bifurcation analysis) of plants with recycle has been an active area of research. Nonlinear analysis provides a global view of system stability and sensitivity over the entire design range. ${ }^{19-24}$ Bifurcation analysis allows one to determine the stability of the designed process and to evaluate the sensitivity of certain design or operating parameters. At the same time, linear analysis focuses on a specific design condition and gives a quantitative description of the linear dynamics (e.g., the transfer function between variables); thus, it is a local method. However, if the model parameters are expressed in terms of system (e.g., rate constant) and design (e.g., conversion) parameters, then the local model can be used to analyze the dynamics over the entire design range; thus, it is a local model for analyzing global behavior. This is exactly the objective of this paper.

The objective of this work is to explore the inherent dynamics of processes with recycle. In Section 2, simple process transfer functions are derived from material balances and expressed in terms of design parameters. In Section 3, control structures are proposed and linear and nonlinear analyses are applied to select the best control structure. Enhanced control system design is discussed in Section 4, followed by conclusions.

\section{Modeling}

2.1. Reactor. Cheng and $\mathrm{Yu}^{25}$ proposed a method for analyzing reaction kinetics with first order $(\mathrm{A} \rightarrow \mathrm{B})$ and recycle. They successfully used the results to design a control structure. We will extend their research to deal with a more complex reaction $(\mathrm{A}+\mathrm{B} \rightarrow 2 \mathrm{C})$.

First, we neglect the effects of the separator and the recycle flow, and we begin with a discussion of the reactor only as shown in Figure $1 \mathrm{~A}$. The two inlet streams $\left(F_{\mathrm{A} \text {,in }}\right.$ and $\left.F_{\mathrm{B} \text {,in }}\right)$ are 
(A)

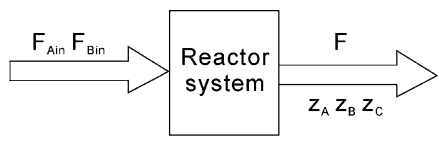

(B)

Recycle $F_{A} F_{B}$

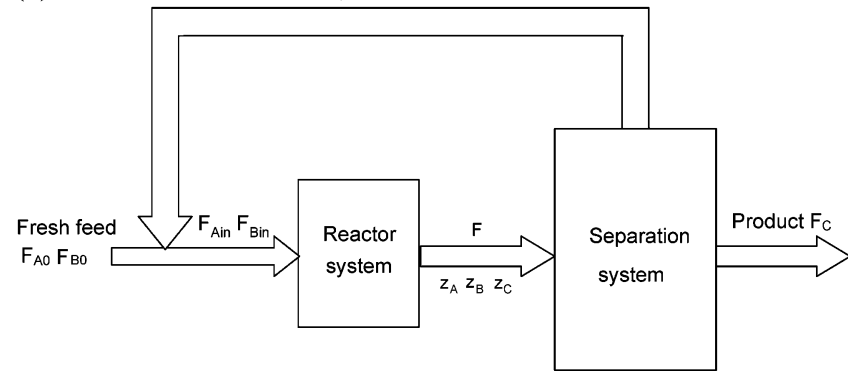

Figure 1. (A) Reactor flowsheet for a ternary system and (B) process with recycle flowsheet for a ternary system.

fed into the reactor. After the reaction takes place in the reactor, the outlet stream $(F)$ contains the components $\mathrm{A}, \mathrm{B}$, and $\mathrm{C}$, with flowrates $F_{\mathrm{A}}, F_{\mathrm{B}}$, and $F_{\mathrm{C}}$, respectively. We assume that the reactor molar holdup is fixed in the system, and that the reaction temperature does not vary enough to influence the kinetics appreciably.

A kinetic rate expression of the following form is assumed,

$$
R=k V_{\mathrm{R}} z_{\mathrm{A}} z_{\mathrm{B}}
$$

where $R$ is the reaction rate $(\mathrm{lbmol} / \mathrm{h}) ; k$ is the rate constant $(1 / \mathrm{h}) ; V_{\mathrm{R}}$ is the reactor volume $(\mathrm{lbmol})$; and $z_{\mathrm{A}}$ and $z_{\mathrm{B}}$ are the mole fractions of the components $\mathrm{A}$ and $\mathrm{B}$, respectively.

The important difference between our approach and others is that we use the reactor outlet flow rates $F_{\mathrm{A}}, F_{\mathrm{B}}$, and $F_{\mathrm{C}}$ as state variables and the reactor inlet flow rates $F_{\mathrm{A} \text {,in }}$ and $F_{\mathrm{B} \text {,in }}$ as manipulated variables. The reactor system becomes a $3 \times 2$ multivariable system.

A material balance on the reactor gives:

$$
\begin{aligned}
& \frac{\mathrm{d} F_{\mathrm{A}}}{\mathrm{d} t}-\frac{F_{\mathrm{A}}}{F} \frac{\mathrm{d} F}{\mathrm{~d} t}=\frac{F F_{\mathrm{A}, \text { in }}}{V_{\mathrm{R}}}-\frac{F F_{\mathrm{A}}}{V_{\mathrm{R}}}-k \frac{F_{\mathrm{A}} F_{\mathrm{B}}}{F} \\
& \frac{\mathrm{d} F_{\mathrm{B}}}{\mathrm{d} t}-\frac{F_{\mathrm{B}}}{F} \frac{\mathrm{d} F}{\mathrm{~d} t}=\frac{F F_{\mathrm{B}, \text { in }}}{V_{\mathrm{R}}}-\frac{F F_{\mathrm{B}}}{V_{\mathrm{R}}}-k \frac{F_{\mathrm{A}} F_{\mathrm{B}}}{F}
\end{aligned}
$$

We perform the linearization and take the Laplace transform of eq 2 and eq 3 , and use $\left(F_{\mathrm{A} \text {,in }}+F_{\mathrm{B} \text {,in }}\right)$ instead of $F$. After rearranging, we get

$$
\left[\begin{array}{l}
F_{\mathrm{A}}(s) \\
F_{\mathrm{B}}(s)
\end{array}\right]=\left[\begin{array}{ll}
g_{11} & g_{12} \\
g_{21} & g_{22}
\end{array}\right]\left[\begin{array}{l}
F_{\mathrm{A}, \text { in }} \\
F_{\mathrm{B}, \text { in }}
\end{array}\right]
$$

where

$$
\begin{aligned}
& g_{11}=\frac{g_{2} g_{5}-g_{4} g_{7}}{g_{1} g_{5}-g_{4} g_{8}} ; \quad g_{12}=\frac{g_{3} g_{5}-g_{4} g_{6}}{g_{1} g_{5}-g_{4} g_{8}} \\
& g_{21}=\frac{g_{7} g_{1}-g_{2} g_{8}}{g_{1} g_{5}-g_{4} g_{8}} ; \quad g_{22}=\frac{g_{6} g_{1}-g_{4} g_{3}}{g_{1} g_{5}-g_{4} g_{8}}
\end{aligned}
$$

where $g_{1}-g_{8}$ are shown in Table 1 .

Here, we want to understand how the steady-state design variables influence the transfer function. Thus, we use the design variables $x$ (conversion defined as $\left.\left(\bar{F}_{\mathrm{A}, \text { in }}-\bar{F}_{\mathrm{A}}\right) / \bar{F}_{\mathrm{A} \text {,in }}\right)$ and $r$ (the
Table 1. Elements of the Transfer Function in Equation 5

$$
\begin{aligned}
& g_{1} \quad s+\frac{\bar{F}}{\overline{V_{\mathrm{R}}}}+k \frac{\overline{F_{\mathrm{B}}}}{F} \\
& g_{2} \frac{\overline{F_{\mathrm{A}}}}{\overline{\bar{F}}} s+\frac{\overline{F_{\mathrm{A}, \text { in }}}}{\overline{V_{\mathrm{R}}}}+\frac{\bar{F}}{\overline{V_{\mathrm{R}}}}-\frac{\overline{F_{\mathrm{A}}}}{\overline{\overline{V_{\mathrm{R}}}}}+k \frac{\overline{F_{\mathrm{A}} F_{\mathrm{B}}}}{\bar{F}^{2}} \\
& \mathrm{~g}_{3} \frac{\overline{F_{\mathrm{A}}}}{\overline{\bar{F}}} s+\frac{\overline{F_{\mathrm{A}, \text { in }}}}{\overline{V_{\mathrm{R}}}}-\frac{\overline{F_{\mathrm{A}}}}{\overline{\overline{V_{\mathrm{R}}}}}+k \frac{\overline{F_{\mathrm{A}} F_{\mathrm{B}}}}{\bar{F}^{2}} \\
& \mathrm{~g}_{4}-k \frac{\overline{F_{\mathrm{A}}}}{\overline{\bar{F}}} \\
& g_{5} \quad s+\frac{\bar{F}}{\overline{V_{\mathrm{R}}}}+k \frac{\overline{F_{\mathrm{A}}}}{\overline{\bar{F}}} \\
& g_{6} \frac{\overline{F_{\mathrm{B}}}}{\overline{\bar{F}}} \mathrm{~s}+\frac{\overline{F_{\mathrm{B}, \mathrm{in}}}}{\overline{V_{\mathrm{R}}}}+\frac{\bar{F}}{\overline{V_{\mathrm{R}}}}-\frac{\overline{F_{\mathrm{B}}}}{\overline{V_{\mathrm{R}}}}+k \frac{\overline{F_{\mathrm{A}} F_{\mathrm{B}}}}{\bar{F}^{2}} \\
& \text { g7 } \frac{\overline{F_{\mathrm{B}}}}{\bar{F}} s+\frac{\overline{F_{\mathrm{B}, \text { in }}}}{\overline{V_{\mathrm{R}}}}-\frac{\overline{F_{\mathrm{B}}}}{\overline{V_{\mathrm{R}}}}+k \frac{\overline{F_{\mathrm{A}} F_{\mathrm{B}}}}{\bar{F}^{2}} \\
& \mathrm{~g}_{8} \quad-k \frac{\overline{F_{\mathrm{B}}}}{\overline{\bar{F}}}
\end{aligned}
$$

ratio of $\bar{F}_{\mathrm{B}, \text { in }} / \bar{F}_{\mathrm{A} \text {,in }}$ ) instead of the steady-state values of the flow rates and reactor molar volume. The result is as follows,

$$
\left[\begin{array}{l}
F_{\mathrm{A}}(s) \\
F_{\mathrm{B}}(s) \\
F_{\mathrm{C}}(s)
\end{array}\right]=\left[\begin{array}{ll}
g_{\mathrm{R} 11} & g_{\mathrm{R} 12} \\
g_{\mathrm{R} 21} & g_{\mathrm{R} 22} \\
g_{\mathrm{R} 31} & g_{\mathrm{R} 32}
\end{array}\right]\left[\begin{array}{l}
F_{\mathrm{A}, \mathrm{in}}(s) \\
F_{\mathrm{B}, \text { in }}(s)
\end{array}\right]
$$

where $g_{\mathrm{R} 11}-g_{\mathrm{R} 32}$ are shown in Table 2 .

Table 2. Elements of the Transfer Function in Equation 6

$$
\begin{aligned}
& g_{\mathrm{R} 11}=\frac{(1-x)}{(1+r)} \\
& s^{2}+\frac{k\left(r^{2}+2 r-x r-x-x^{2}\right)}{(1+r) x} s+\frac{k^{2}(1-x)(r-x)\left(2 r x+r+r^{2}-2 x^{2}\right)}{(1+r)^{2} x^{2}} \\
& s^{2}+\frac{k(2 r-x-r x)}{(1+r) x} s+\frac{k^{2}(r-x)(1-x)\left(r-x^{2}\right)}{(1+r)^{2} x^{2}} \\
& g_{\mathrm{R} 12}=\frac{(1-x)}{(1+r)} \frac{s^{2}+\frac{k\left(r-x^{2}\right)}{(1+r) x} s+\frac{k^{2}(1-x)(r-x)(r-2 x-1)}{(1+r)^{2} x}}{s^{2}+\frac{k(2 r-x-r x)}{(1+r) x} s+\frac{k^{2}(r-x)(1-x)\left(r-x^{2}\right)}{(1+r)^{2} x^{2}}} \\
& g_{\mathrm{R} 21}=\frac{(r-x)}{(1+r)} \frac{s^{2}+\frac{k\left(r-x^{2}\right)}{(1+r) x} s+\frac{k^{2}(1-x)(r-x)(1-r-2 x)}{(1+r)^{2} x}}{s^{2}+\frac{k(2 r-x-r x)}{(1+r) x} s+\frac{k^{2}(r-x)(1-x)\left(r-x^{2}\right)}{(1+r)^{2} x^{2}}} \\
& g_{\mathrm{R} 22}=\frac{(r-x)}{(1+r)} \\
& \frac{s^{2}+\frac{k\left(2 r-x r-x-x^{2}+1\right)}{(1+r) x} s+\frac{k^{2}(1-x)(r-x)\left(2 x+r+1-2 x^{2}\right)}{(1+r)^{2} x^{2}}}{k-x-r x)} \\
& s^{2}+\frac{k(2 r-x-r x)}{(1+r) x} s+\frac{k^{2}(r-x)(1-x)\left(r-x^{2}\right)}{(1+r)^{2} x^{2}} \\
& g_{\mathrm{R} 31}=\frac{2 x}{(1+r)} \frac{s^{2}+\frac{k\left(r-x^{2}\right)}{(1+r) x} s+\frac{k^{2}(1-x)(r-x)\left(r^{2}-r+x r+x-2 x^{2}\right)}{(1+r)^{2} x^{2}}}{s^{2}+\frac{k(2 r-x-r x)}{(1+r) x} s+\frac{k^{2}(r-x)(1-x)\left(r-x^{2}\right)}{(1+r)^{2} x^{2}}} \\
& g_{\mathrm{R} 32}=\frac{2 x}{(1+r)} \frac{s^{2}+\frac{k\left(r-x^{2}\right)}{(1+r) x} s+\frac{k^{2}(1-x)(r-x)\left(1-r+x r+x-2 x^{2}\right)}{(1+r)^{2} x^{2}}}{s^{2}+\frac{k(2 r-x-r x)}{(1+r) x} s+\frac{k^{2}(r-x)(1-x)\left(r-x^{2}\right)}{(1+r)^{2} x^{2}}}
\end{aligned}
$$


For a multivariable system, the input and output relationship cannot be understood as easily as it can be for a single-input single-output (SISO) system. For the reactor system studied here, there exists a relation between two fresh feeds. That is, $F_{\mathrm{B}, \text { in }}(\mathrm{s})$ $=r F_{\mathrm{A}, \text { in }}(\mathrm{s})$ and $F_{\mathrm{B}, \text { in }}(\mathrm{s})+F_{\mathrm{A}, \text { in }}(\mathrm{s})=F_{\text {in }}(\mathrm{s})\left[F_{\mathrm{A}, \text { in }}(\mathrm{s})=F_{\text {in }}(\mathrm{s}) /(1\right.$ $\left.+r) ; F_{\mathrm{B}, \text { in }}(\mathrm{s})=r F_{\text {in }}(\mathrm{s}) /(1+r)\right]$. Using these two equations, we can rewrite eq 5 as

$$
\left[\begin{array}{l}
F_{\mathrm{A}}(s) \\
F_{\mathrm{B}}(s) \\
F_{\mathrm{C}}(s)
\end{array}\right]=\left[\begin{array}{l}
g_{\mathrm{T} 1} \\
g_{\mathrm{T} 2} \\
g_{\mathrm{T} 3}
\end{array}\right]\left[F_{\mathrm{in}}(s)\right]
$$

where

$$
\begin{gathered}
g_{\mathrm{T} 1}=\frac{(1-x)}{(1+r)} \frac{s+\frac{k\left(r+r x-2 x^{2}\right)}{(1+r) x}}{s+\frac{k\left(r-x^{2}\right)}{(1+r) x}} ; \\
g_{\mathrm{T} 2}=\frac{(r-x)}{(1+r)} \frac{s+\frac{k\left(r+x-2 x^{2}\right)}{(1+r) x}}{s+\frac{k\left(r-x^{2}\right)}{(1+r) x}} ; \\
g_{\mathrm{T} 3}=\frac{2 x}{(1+r)} \frac{k+\frac{k(1+r-2 x)}{(1+r)}}{s+\frac{k\left(r-x^{2}\right)}{(1+r) x}}
\end{gathered}
$$

Next, the reactant distribution $\left(\lambda=z_{\mathrm{B}} / z_{\mathrm{A}}\right)$ in the reactor and the product molar fraction $\left(z_{\mathrm{C}}\right)$ are substituted in place of $x$ and $r$ to give

$$
\left[\begin{array}{l}
F_{\mathrm{A}}(s) \\
F_{\mathrm{B}}(s) \\
F_{\mathrm{C}}(s)
\end{array}\right]=\left[\begin{array}{l}
g_{\mathrm{T} 1} \\
g_{\mathrm{T} 2} \\
g_{\mathrm{T} 3}
\end{array}\right]\left[F_{\mathrm{in}}(s)\right]
$$

where

$$
\begin{aligned}
& g_{\mathrm{T} 1}=\frac{\left(1-z_{\mathrm{C}}\right)}{(1+\lambda)} \cdot \frac{s+\frac{k\left(1-z_{\mathrm{C}}\right)\left(\lambda z_{\mathrm{C}}+2 \lambda^{2} z_{\mathrm{C}}+z_{\mathrm{C}}+2 \lambda\right)}{z_{\mathrm{C}}(1+\lambda)^{2}}}{s+\frac{k\left(1-z_{\mathrm{C}}\right)\left(\lambda^{2} z_{\mathrm{C}}+z_{\mathrm{C}}+2 \lambda\right)}{z_{\mathrm{C}}(1+\lambda)^{2}}} \\
& g_{\mathrm{T} 2}=\frac{\lambda\left(1-z_{\mathrm{C}}\right)}{(1+\lambda)} \cdot \frac{s+\frac{k\left(1-z_{\mathrm{C}}\right)\left(\lambda z_{\mathrm{C}}+\lambda^{2} z_{\mathrm{C}}+2 z_{\mathrm{C}}+2 \lambda\right)}{z_{\mathrm{C}}(1+\lambda)^{2}}}{s+\frac{k\left(1-z_{\mathrm{C}}\right)\left(\lambda^{2} z_{\mathrm{C}}+z_{\mathrm{C}}+2 \lambda\right)}{z_{\mathrm{C}}(1+\lambda)^{2}}} \\
& g_{\mathrm{T} 3}=z_{\mathrm{C}} \frac{k\left(1-z_{\mathrm{C}}\right)}{s+\frac{k\left(1-z_{\mathrm{C}}\right)\left(\lambda^{2} z_{\mathrm{C}}+z_{\mathrm{C}}+2 \lambda\right)}{z_{\mathrm{C}}(1+\lambda)^{2}}}
\end{aligned}
$$

From the open-loop transfer function, the pole of the reactor system is

$$
p=-\frac{k\left(1-z_{\mathrm{C}}\right)\left(\lambda^{2} z_{\mathrm{C}}+z_{\mathrm{C}}+2 \lambda\right)}{z_{\mathrm{C}}(1+\lambda)^{2}}
$$

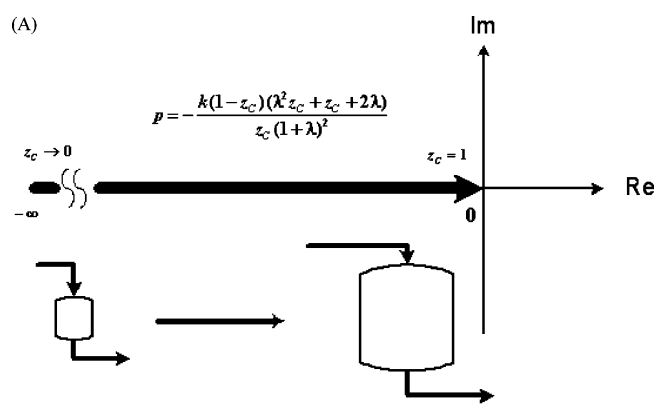

(B)

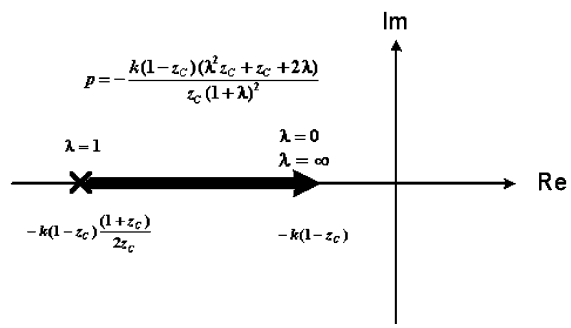

Figure 2. Design-stage root locus plot for the reactor system.

A plot of the poles of the transfer function versus design parameters, hereafter called a "design-stage root locus plot", is shown in Figure $2 \mathrm{~A}$. When $z_{\mathrm{C}} \approx 0$, the pole becomes $-\infty$. This means that the dynamics of the reactor are very fast, and that the reactor size is very small. Conversely, when $z_{C}=1$, the dynamic response will be slow. The other variable is $\lambda$. If $\lambda=$ 1 , the pole will be located at $p=-k\left(1-z_{\mathrm{C}}{ }^{2}\right) /\left(2 z_{\mathrm{C}}\right)$. When $\lambda \approx$ $0($ or $\infty)$, the pole becomes $-k\left(1-z_{\mathrm{C}}\right)$. From the above results, the dynamic response will be fastest when $\lambda=1$. The results are shown in Figure 2b. It is also shown that, for an isothermal CSTR reactor, the dynamic response will always be stable. However, as $z_{\mathrm{C}}$ approaches 1 , the pole of the system approaches 0 . This corresponds to a reactor of infinite size; the system becomes an integrator.

2.2. Reactor/Separator. To make efficient use of the reactant, the unreacted reactant should be recycled back to the reactor via a separator. This kind of material recycling system can be considered as a positive feedback system. Some researchers have analyzed the characteristics of positive feedback systems. ${ }^{1,5,18}$

Our recycling system contains a reactor and separator. We assume that the column is a perfect separator. The unreacted reactants $\mathrm{A}$ and $\mathrm{B}\left(F_{\mathrm{A}}, F_{\mathrm{B}}\right)$, are recycled back to the reactor, and the product $\mathrm{C}$ is collected from the bottom of the second distillation column. Compared with the reactor dynamics, we assume that the dynamics of the separation system are fast and can be neglected. Using the reactant molar flow rates $\left(F_{\mathrm{A}}\right.$ and $\left.F_{\mathrm{B}}\right)$ as the state variables, we can obtain the transfer functions for a reactor/separator with a recycling system as follows,

$$
\begin{aligned}
& G_{\mathrm{P}}^{\mathrm{u}}=G_{\mathrm{R}}^{\mathrm{u}}\left(1-G_{\mathrm{R}}^{\mathrm{u}}\right)^{-1} \\
& G_{\mathrm{P}}^{\mathrm{d}}=G_{\mathrm{R}}^{\mathrm{d}}\left(1-G_{\mathrm{R}}^{\mathrm{u}}\right)^{-1}
\end{aligned}
$$

where $G_{\mathrm{R}}^{\mathrm{u}}$ and $G_{\mathrm{P}}^{\mathrm{d}}$ are the transfer functions of the reactant and product, respectively, in the reactor. Thus, we can obtain the transfer function of the system with recycle,

$$
\left[\begin{array}{l}
F_{\mathrm{A}}(s) \\
F_{\mathrm{B}}(s) \\
F_{\mathrm{C}}(s)
\end{array}\right]=\left[\begin{array}{ll}
g_{\mathrm{P} 11} & g_{\mathrm{P} 12} \\
g_{\mathrm{P} 21} & g_{\mathrm{P} 22} \\
g_{\mathrm{P} 31} & g_{\mathrm{P} 32}
\end{array}\right]\left[\begin{array}{l}
F_{\mathrm{A} 0}(s) \\
F_{\mathrm{B} 0}(s)
\end{array}\right]
$$

where $F_{\mathrm{A} 0}$ and $F_{\mathrm{B} 0}$ are the fresh feeds of $\mathrm{A}$ and $\mathrm{B}$, respectively. $F_{\mathrm{A}}, F_{\mathrm{B}}$, and $F_{\mathrm{C}}$ are the molar flow rates of the reactor effluent. The elements of the transfer function matrix are as follows: 


$$
\begin{aligned}
& g_{\mathrm{P} 11}=\frac{1-z_{\mathrm{C}}}{z_{\mathrm{C}}(1+\lambda)} \frac{s^{2}+\frac{k\left(1-z_{\mathrm{C}}\right)\left(2 \lambda z_{\mathrm{C}}+3 \lambda^{2} z_{\mathrm{C}}+z_{\mathrm{C}}+2 \lambda\right)}{z_{\mathrm{C}}(1+\lambda)^{2}} s+\frac{2 k^{2} \lambda\left(1-z_{\mathrm{C}}\right)^{2}\left(2 \lambda z_{\mathrm{C}}-\lambda+1\right)}{s\left(s+k\left(1-z_{\mathrm{C}}\right)\right)}}{z_{\mathrm{C}}(1+\lambda)^{3}} \\
& g_{\mathrm{P} 12}=\frac{1-z_{\mathrm{C}}}{z_{\mathrm{C}}(1+\lambda)} \frac{s^{2}+\frac{k\left(1-z_{\mathrm{C}}\right)\left(z_{\mathrm{C}}+\lambda^{2} z_{\mathrm{C}}+2 \lambda\right)}{z_{\mathrm{C}}(1+\lambda)^{2}} s-\frac{2 k^{2} \lambda\left(1-z_{\mathrm{C}}\right)^{2}\left(2 \lambda z_{\mathrm{C}}-\lambda+1\right)}{z_{\mathrm{C}}(1+\lambda)^{3}}}{s\left(s+k\left(1-z_{\mathrm{C}}\right)\right)} \\
& g_{\mathrm{P} 21}=\frac{\lambda\left(1-z_{\mathrm{C}}\right)}{z_{\mathrm{C}}(1+\lambda)} \frac{z_{\mathrm{C}}(1+\lambda)^{2}}{s\left(s+k\left(1-z_{\mathrm{C}}\right)\right)} \\
& g_{\mathrm{P} 22}^{2}+\frac{k\left(1-z_{\mathrm{C}}\right)\left(\lambda^{2} z_{\mathrm{C}}+z_{\mathrm{C}}+2 \lambda\right)}{z_{\mathrm{C}}(1+\lambda)} s-\frac{2 k^{2} \lambda\left(1-z_{\mathrm{C}}\right)^{2}\left(2 z_{\mathrm{C}}-1+\lambda\right)}{z_{\mathrm{C}}(1+\lambda)^{3}} \\
& g_{\mathrm{P} 31}=1 \\
& g_{\mathrm{P} 32}=1 \\
& s^{2}+\frac{k\left(1-z_{\mathrm{C}}\right)\left(2 \lambda z_{\mathrm{C}}+3 z_{\mathrm{C}}+\lambda^{2} z_{\mathrm{C}}+2 \lambda\right)}{z_{\mathrm{C}}(1+\lambda)^{2}} s k^{2} \lambda\left(1-z_{\mathrm{C}}\right)^{2}\left(2 z_{\mathrm{C}}-1+\lambda\right) \\
& z_{\mathrm{C}}(1+\lambda)^{3}
\end{aligned}
$$

The block diagram of the reactor/separator with recycle process is shown in Figure 3.

2.3. Observations. From Section 2.2, we can make some observations about the process transfer function of a ternary system with a recycling plant:

(1) From the input-output point of view, if perfect level control in a reactor and perfect separation can be achieved, then regardless of the design alternatives (the mole fraction of component $\mathrm{C}\left(z_{\mathrm{C}}\right)$ and the reactant distribution $(\lambda)$ ), nearinstantaneous production rate changes can always be achieved.

(2) As for the reactant distribution $(\lambda)$ in our design, the pole of the flow dynamics is invariant. It is fixed at $p=-k\left(1-z_{\mathrm{C}}\right)$ and is not effected by the reactant distribution.

(3) If we change the mole fraction of component $\mathrm{C}$ from 0 to 1 (this means that we change the relative sizes of the reactor and separator), then the poles of the internal flow dynamics

(a)

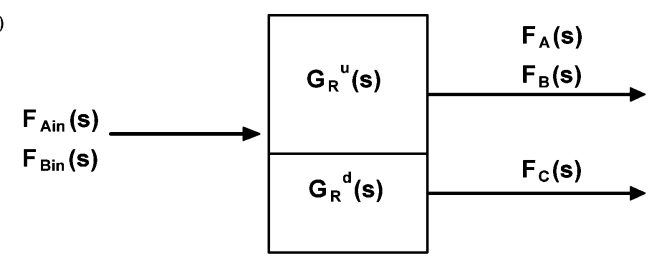

(b)
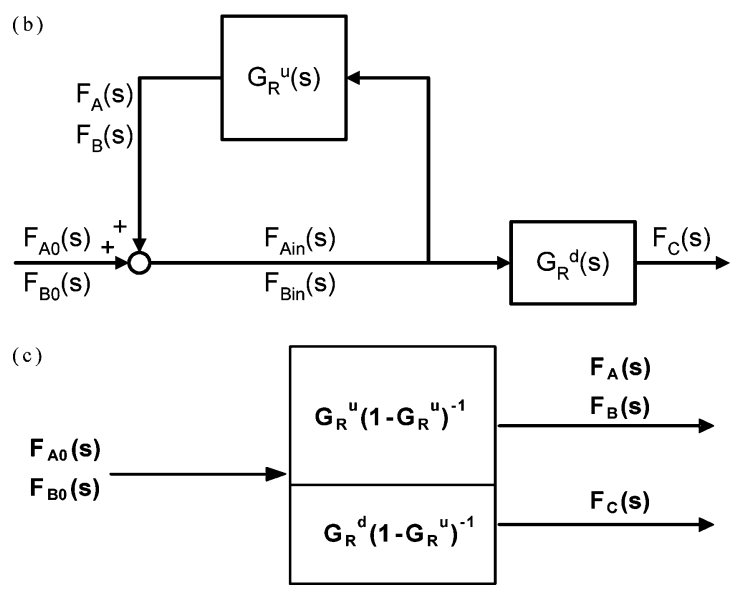

Figure 3. Block diagram of the process with recycle.
$\left(F_{\mathrm{A}}(s) / F_{\mathrm{A} 0}(s), \quad F_{\mathrm{B}}(s) / F_{\mathrm{A} 0}(s), \quad F_{\mathrm{A}}(s) / F_{\mathrm{B} 0}(s), \quad F_{\mathrm{B}}(s) / F_{\mathrm{B} 0}(s)\right)$ will change from $-k$ to 0 . This result is shown in Figure 4 . For a large reaction rate constant $(k)$, the system pole will be distant from the origin, which means that the internal dynamic response will become faster.

(4) Equation 11 shows the transfer function of the recycle system. There is an integrator in every element of the transfer function matrix $\left(g_{\mathrm{P} 11}-g_{\mathrm{P} 22}\right)$. From eq 11 , we can see that the behavior will be unstable in the open-loop dynamic response if the two fresh feeds $\left(F_{\mathrm{A} 0}\right.$ and $\left.F_{\mathrm{B} 0}\right)$ do not exactly match. When the two fresh feeds operate at the same value, there will be a pole-zero cancellation $(s / s)$ in the four elements of the transfer function. In addition, the internal flow dynamics will remain stable. If $F_{\mathrm{A} 0}=F_{\mathrm{B} 0}$, the constant term in the numerator of ( $g_{\mathrm{P} 11}$ $\left.+g_{\mathrm{P} 12}\right)$ will cancel. For example, $F_{\mathrm{A}}(s)=g_{\mathrm{P} 11} F_{\mathrm{A} 0}(s)+g_{\mathrm{P} 12} F_{\mathrm{B} 0}-$ $(s)$. If $F_{\mathrm{A} 0}(s)=F_{\mathrm{B} 0}(s)$, then the constant terms in the numerators of $g_{\mathrm{P} 11}$ and $g_{\mathrm{P} 12}$ will cancel when they are added because they are of opposite sign. Figure 5 shows the dynamic response when step changes of unequal magnitude are made in the fresh feed flow rates. As expected, the internal recycle flows are unstable.

It should be emphasized here that these observations are based on the assumptions of the perfect level control and perfect separation. Figure 6 shows a comparison between the dynamic responses of the linear and rigorous process models. In addition to being nonlinear, the rigorous model includes realistic separation dynamics. Both the linear and nonlinear models are based on the process design and operating point identified by Cheng

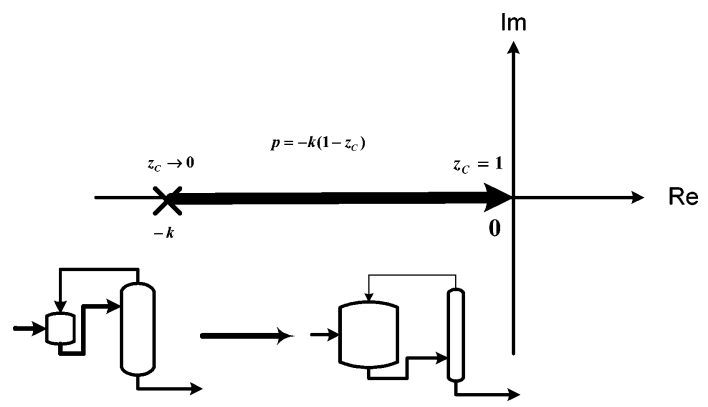

Figure 4. Design stage root locus plot diagram of a reactor/separator with recycle. 

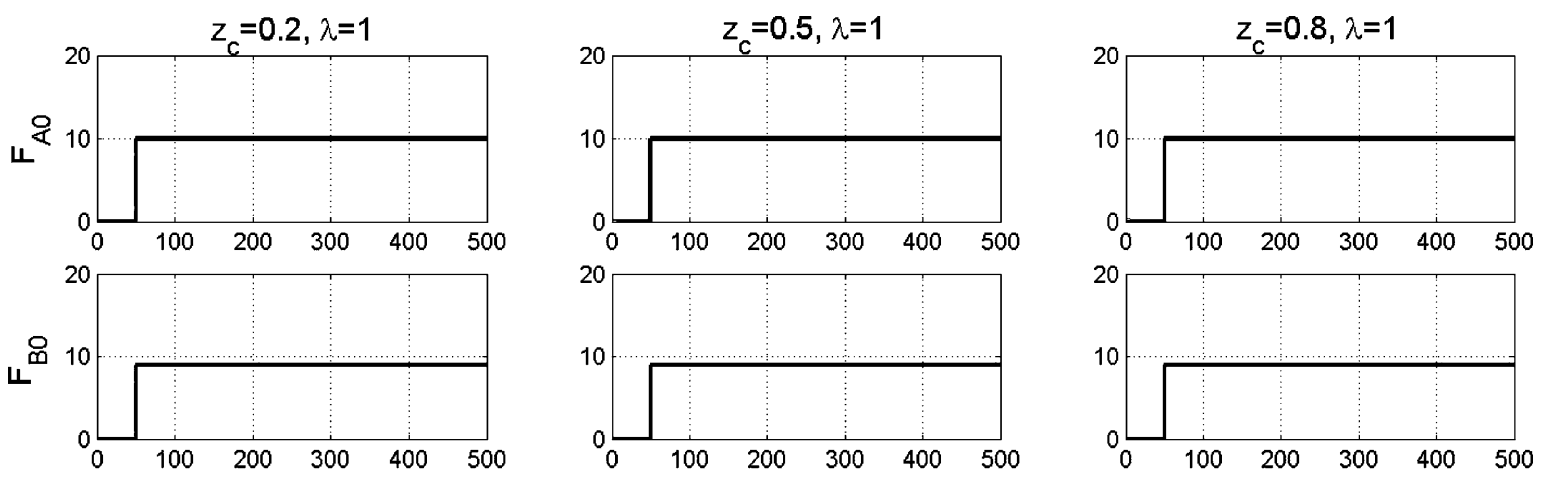

$\Perp^{\varangle}$
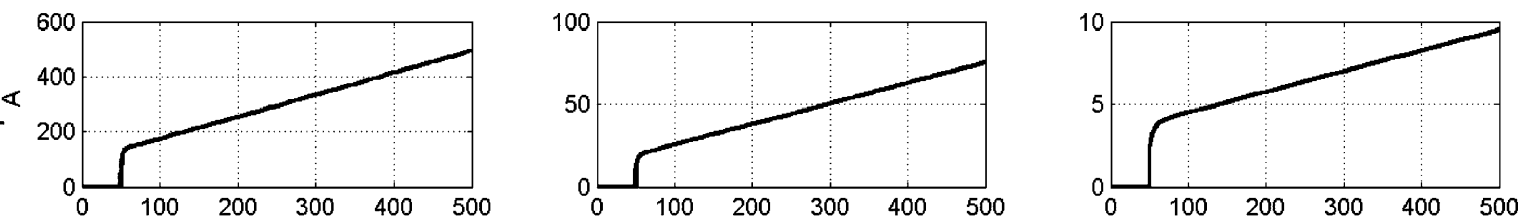

$u^{\infty}$
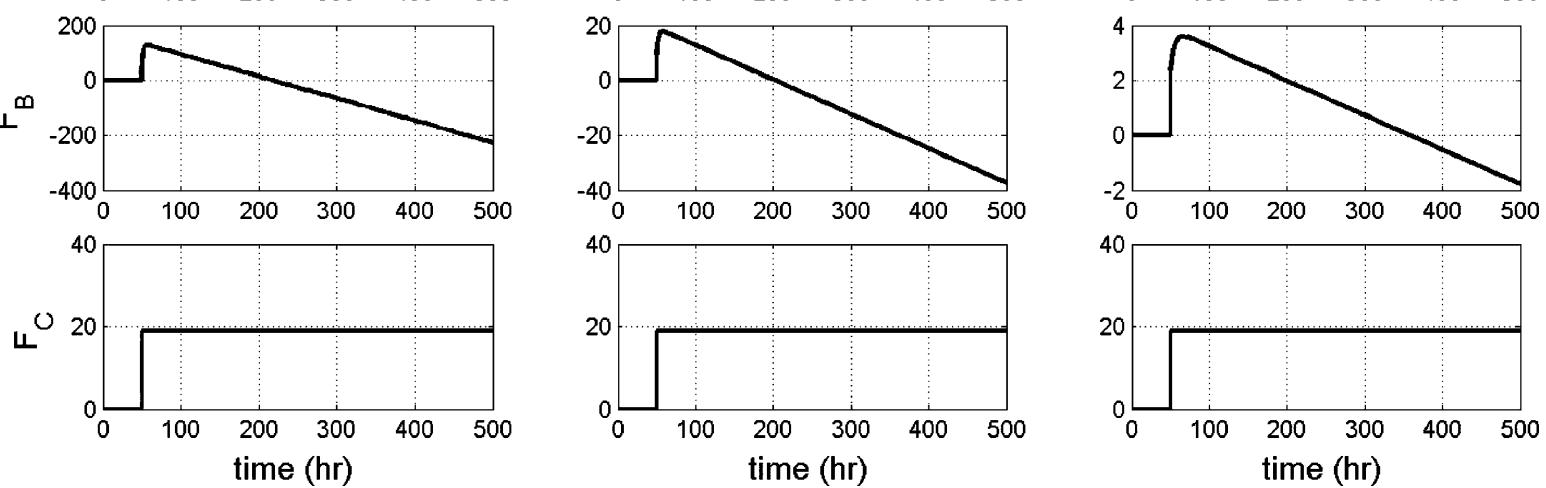

Figure 5. Dynamic response of the linear model to step changes in $F_{\mathrm{A} 0}$ and $F_{\mathrm{B} 0}$ of unequal magnitude. The internal streams $F_{\mathrm{A}}$ and $F_{\mathrm{B}}$ are unstable. All flow rates are in deviation variables.
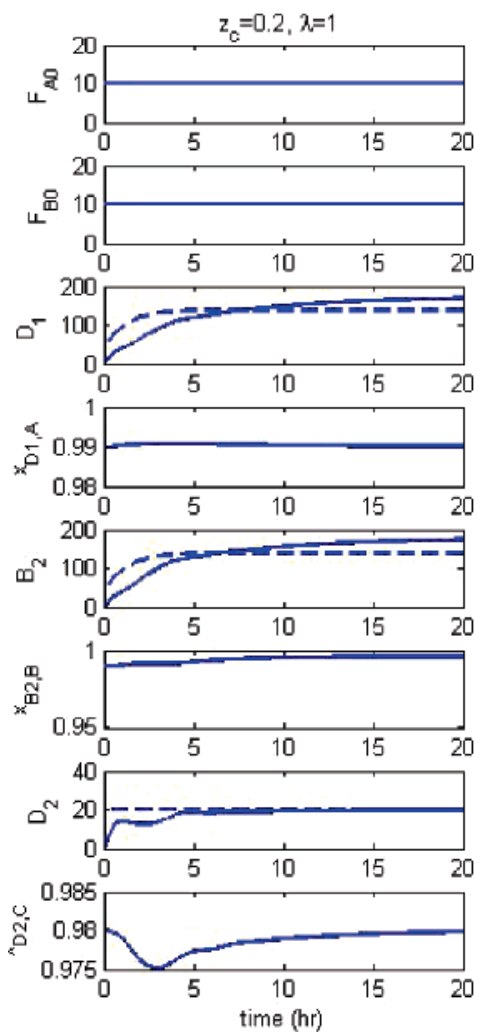

$\tau_{c}=0.5, \lambda=1$
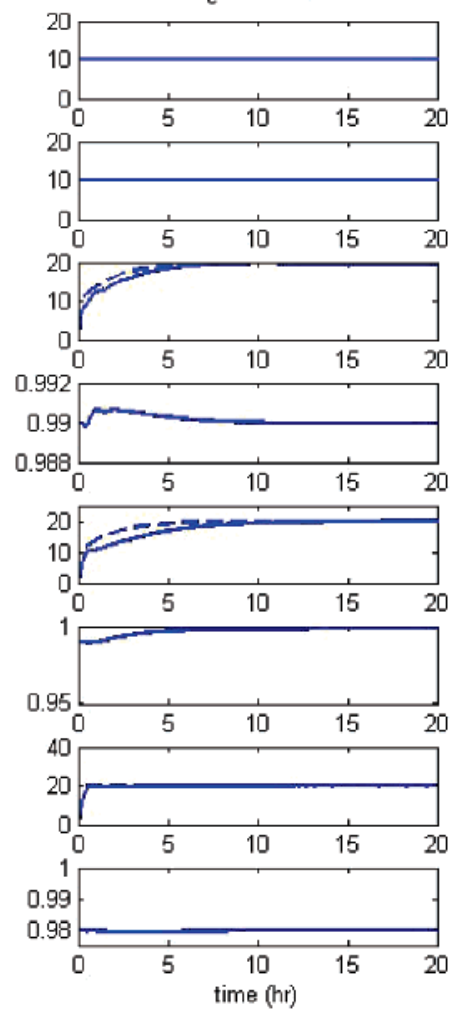
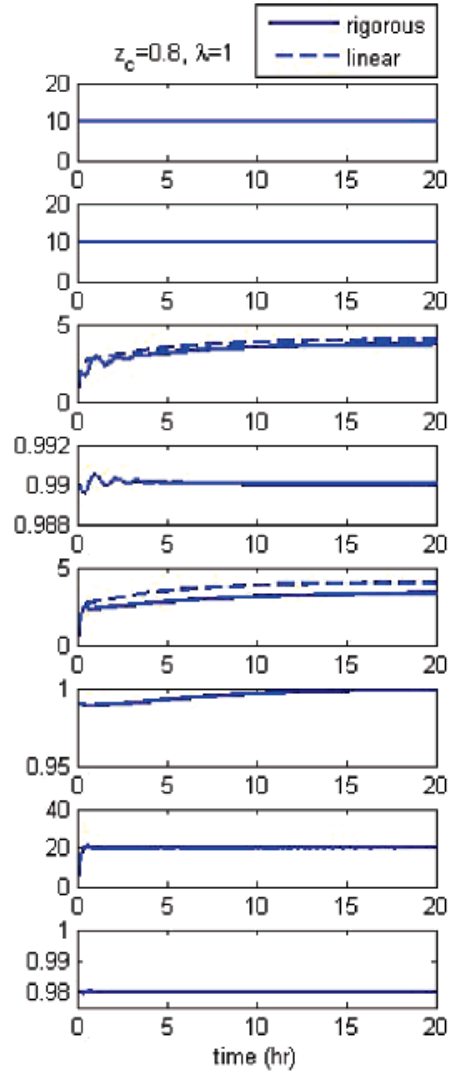

Figure 6. Dynamic response after a 10\% production rate increase for both the linear and nonlinear reactor/separator with perfect level control. 


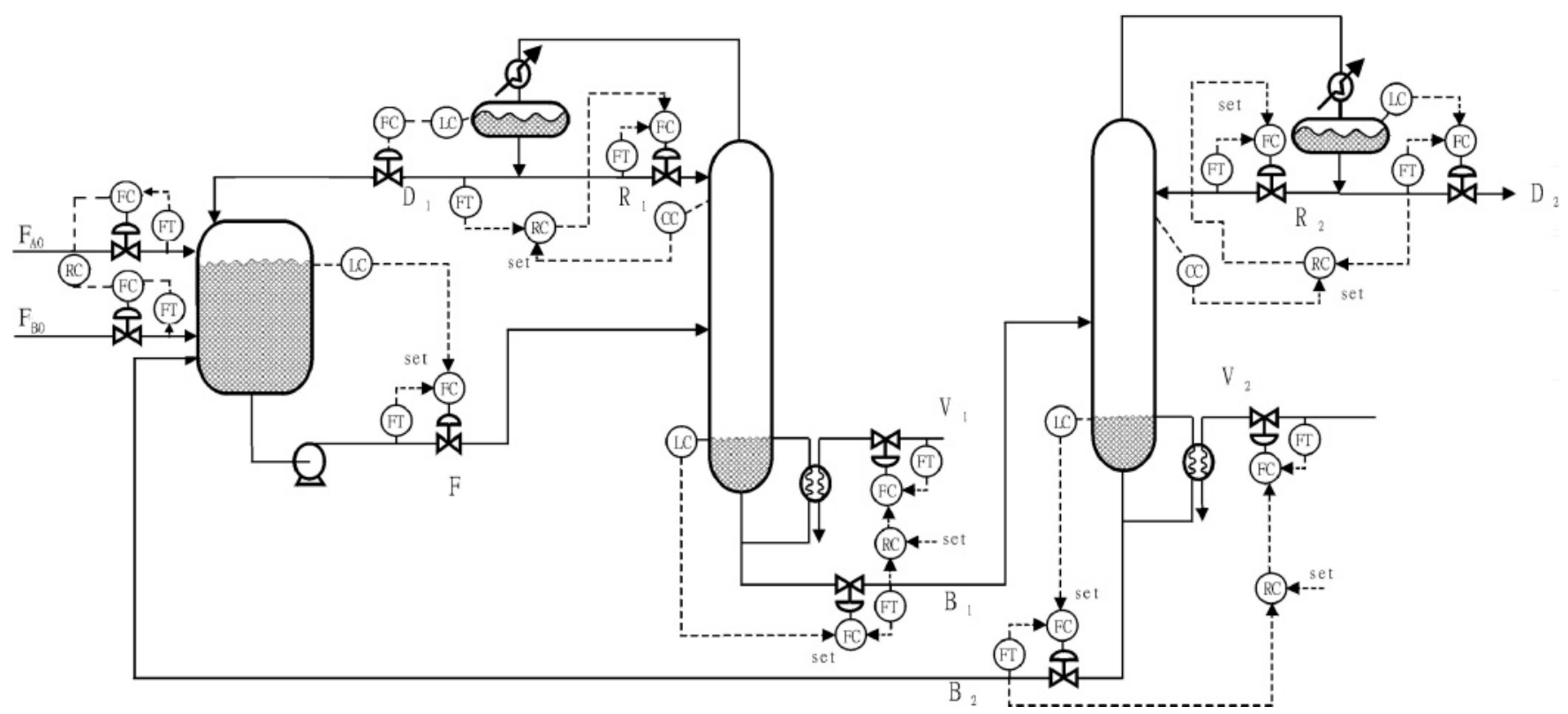

Figure 7. CS1 control structure.

and $\mathrm{Yu}^{27}$ and discussed in more detail in Section 3.5. Although the transient responses of some variables are quantitatively different, the trends and qualitative behavior of the two models are similar.

Observations confirm the point made by Luyben: ${ }^{3}$ all these competing effects result in a process in which the external dynamics of various alternative designs are quite similar. Equation 11 is the most important result of this work because it points out that different designs result in exactly the same external dynamics, i.e., instantaneous direct throughput with a gain of 1. Moreover, perfect production control can be achieved. From eq 11, there exists an integrator in the transfer function. This means that the system will be unstable if the two fresh feeds are unequal.

\section{Control Structure Selection}

From the analysis of Section 2, we anticipate that the plant may have operational difficulties if a poor control structure is selected. In this section, we propose and evaluate four different control structures. One control structure uses a feed-forward ratio controller to set the fresh feed flow rate of one species. However, from the open-loop analysis, we anticipate that this control structure will not be feasible because the reactant flow rates cannot be balanced down to the last molecule. Therefore, we propose three additional control structures which regulate the fresh feed of one or both reactants using feedback control.

3.1 Candidate Control Structures. The ternary plant with recycle under study includes one reactor and two distillation columns. Figures 7-9 show the four control structures. In the first case, the fresh feed flow of component $\mathrm{B}\left(F_{\mathrm{B} 0}\right)$ is ratioed to $F_{\mathrm{A} 0}$ as shown in Figure 7 and denoted as CS1 hereafter. In the second case, the recycling flow $\left(D_{\mathrm{T}, \mathrm{A}}=B_{2}+F_{\mathrm{B} 0}\right.$ or $D_{\mathrm{T}, \mathrm{B}}$ $\left.=D_{1}+F_{\mathrm{A} 0}\right)$ is ratioed to $F_{\mathrm{A} 0}\left(\right.$ or $\left.F_{\mathrm{B} 0}\right)$, and the fresh feed is manipulated to control the level in the reflux condenser. These are called CS2A and CS2B hereafter (see Figure 8). In the third case, the production rate is set by adjusting the two recycle flows $\left(D_{\mathrm{T}, \mathrm{B}}=B_{2}+F_{\mathrm{B} 0}\right.$ or $\left.D_{\mathrm{T}, \mathrm{A}}=D_{1}+F_{\mathrm{A} 0}\right)$ simultaneously, and this is called CS3 hereafter (see Figure 9). Pairings between all controlled and manipulated variables for all control structures are summarized in Table 3.

Note that constant boilup ratio has been assumed for simplicity. If it were necessary to control the bottoms composi- tion of either column tightly, a composition controller could be cascaded onto the boilup ratio controller.

Note also that, for this case study, we have selected a process with two distillation columns and we have assumed that the desired product has a relative volatility between that of the two reactant species. However, the methodology demonstrated here is applicable to processes with other separation system configurations, provided that the dynamics of the separation system are fast compared to those of the reactor. The control structure would have to be suitably modified to accommodate the different configuration.

3.2. Global Analysis: Eliminate Unstable Control Structures. Gadewar et al. ${ }^{26}$ proposed a systematic method to analyze the material balance of a complex plant. On the basis of their methodology, we will analyze our ternary recycle system. Figure 1 shows the process flowsheet. In the process, we have two fresh feeds $\left(F_{\mathrm{A} 0}, F_{\mathrm{B} 0}\right)$ and one product stream $\left(F_{\mathrm{C}}\right)$. In the recycling system, three streams can be adjusted, but two material balances must be maintained:

$$
\begin{aligned}
& F_{\mathrm{A} 0}={ }^{1} /{ }_{2} F_{\mathrm{C}} \\
& F_{\mathrm{B} 0}={ }^{1} /{ }_{2} F_{\mathrm{C}}
\end{aligned}
$$

The system has one degree of freedom. If we fix one stream, the other two steams will be determined. To keep the degree of freedom and the material balance (eqs 12 and 13), the two fresh feeds must be equal. The point is proved by our result (shown in eq 11). For the traditional control structure, the two fresh feed are fixed. If the flows are not exactly matched, the transfer function of eq 11 shows that the integrator cannot be canceled. One reactant will accumulate in the system, and the flow rate of the recycle stream for the reactant will increase. At the same time, the flow rate of the other reactant species will decrease until the process becomes inoperable.

CS1 is shown in Figure 7. The fresh feed flow of component $B\left(F_{\mathrm{B} 0}\right)$ is ratioed to $F_{\mathrm{A} 0}$. If two unmatched fresh feed flows exist, the transfer function of eq 11 shows that the integrator cannot be canceled. One reactant will accumulate in the system, and the recycle flow rate of that reactant will increase. Conversely, the other reactant stream recycle flow rate will decrease. Finally, the system will become unstable. Thus, CS1 cannot work. 

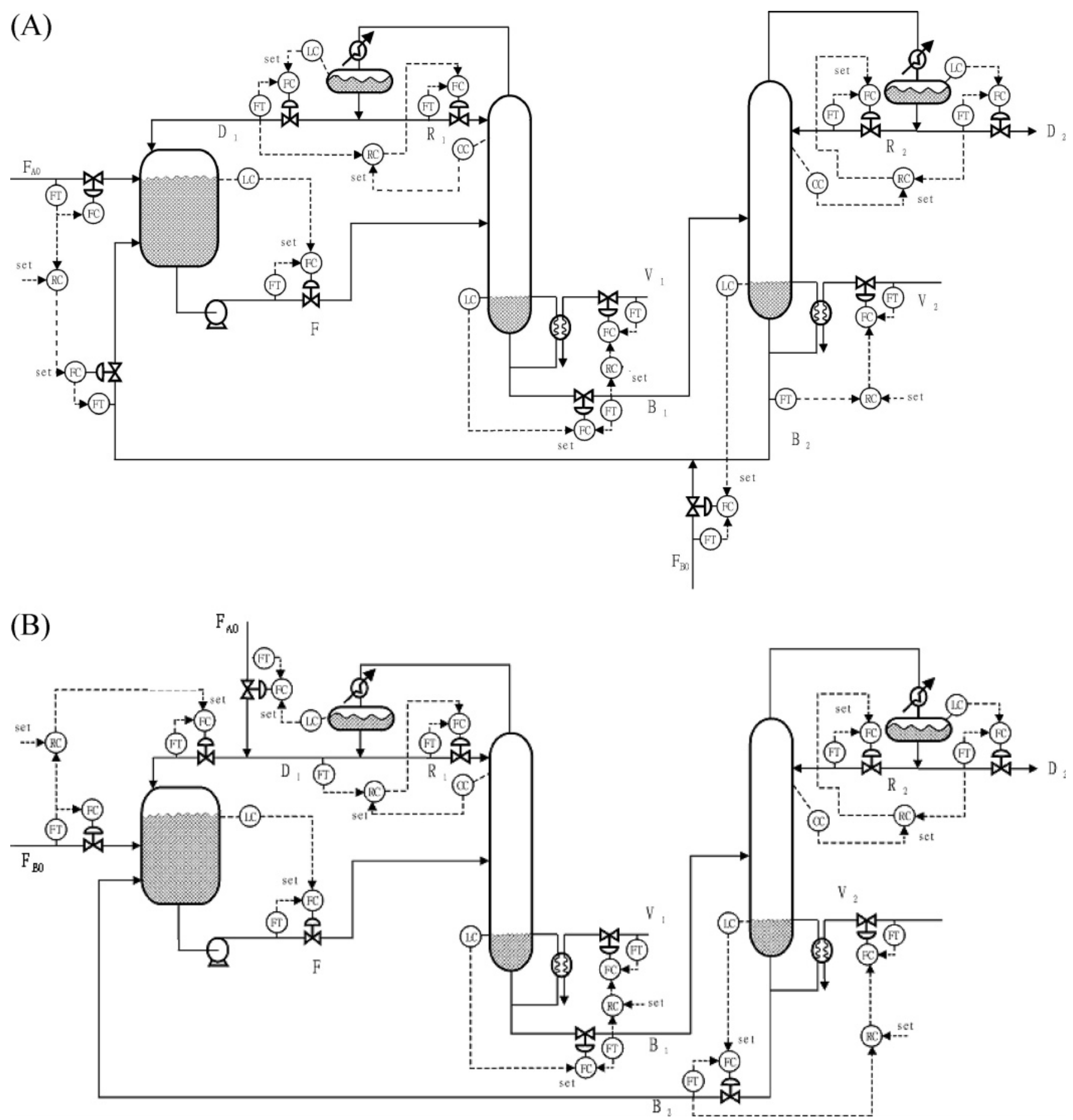

Figure 8. Control structure: (A) $\mathrm{CS} 2 \mathrm{~A}$ and (B) CS2B.

Table 3. Controller Pairings for the Three Control Structures

\begin{tabular}{|c|c|c|c|c|}
\hline \multirow[b]{2}{*}{ controlled } & \multicolumn{4}{|c|}{ manipulated } \\
\hline & CS1 & $\mathrm{CS} 2 \mathrm{~A}$ & $\mathrm{CS} 2 \mathrm{~B}$ & CS3 \\
\hline reactor level & reactor effluent flow & reactor effluent flow & reactor effluent flow & reactor effluent flow \\
\hline $\mathrm{C} 1$ bottom level & $\mathrm{C} 1$ bottom flow & $\mathrm{C} 1$ bottom flow & $\mathrm{C} 1$ bottom flow & $\mathrm{C} 1$ bottom flow \\
\hline $\mathrm{C} 1$ reflux level & $\mathrm{C} 1$ distillate flow & $\mathrm{C} 1$ distillate flow & fresh feed of A & fresh feed of A \\
\hline $\mathrm{C} 1$ boilup ratio & $\mathrm{C} 1$ boilup rate & $\mathrm{C} 1$ boilup rate & $\mathrm{C} 1$ boilup rate & $\mathrm{C} 1$ boilup rate \\
\hline recycle comp. & $\mathrm{C} 1$ reflux ratio & $\mathrm{C} 1$ reflux ratio & $\mathrm{C} 1$ reflux ratio & $\mathrm{C} 1$ reflux ratio \\
\hline $\mathrm{C} 2$ bottom level & C2 bottom flow & fresh feed of B & C2 bottom flow & fresh feed of B \\
\hline C2 reflux level & $\mathrm{C} 2$ distillate flow & $\mathrm{C} 2$ distillate flow & $\mathrm{C} 2$ distillate flow & $\mathrm{C} 2$ distillate flow \\
\hline $\mathrm{C} 2$ boilup ratio & $\mathrm{C} 2$ boilup rate & $\mathrm{C} 2$ boilup rate & $\mathrm{C} 2$ boilup rate & $\mathrm{C} 2$ boilup rate \\
\hline product comp. & $\mathrm{C} 2$ reflux ratio & $\mathrm{C} 2$ reflux ratio & $\mathrm{C} 2$ reflux ratio & $\mathrm{C} 2$ reflux ratio \\
\hline
\end{tabular}

From global analysis, we can eliminate the unworkable control structure. Candidate control structures can be reduced. In this example, CS2 and CS3 will be considered in the following analysis.
3.3. Local Analysis: Select Preferable Dynamics. From global analysis, we can eliminate the unworkable control structure (CS1). Operability and stability will be considered for the remaining control structures (CS2 and CS3). Although 


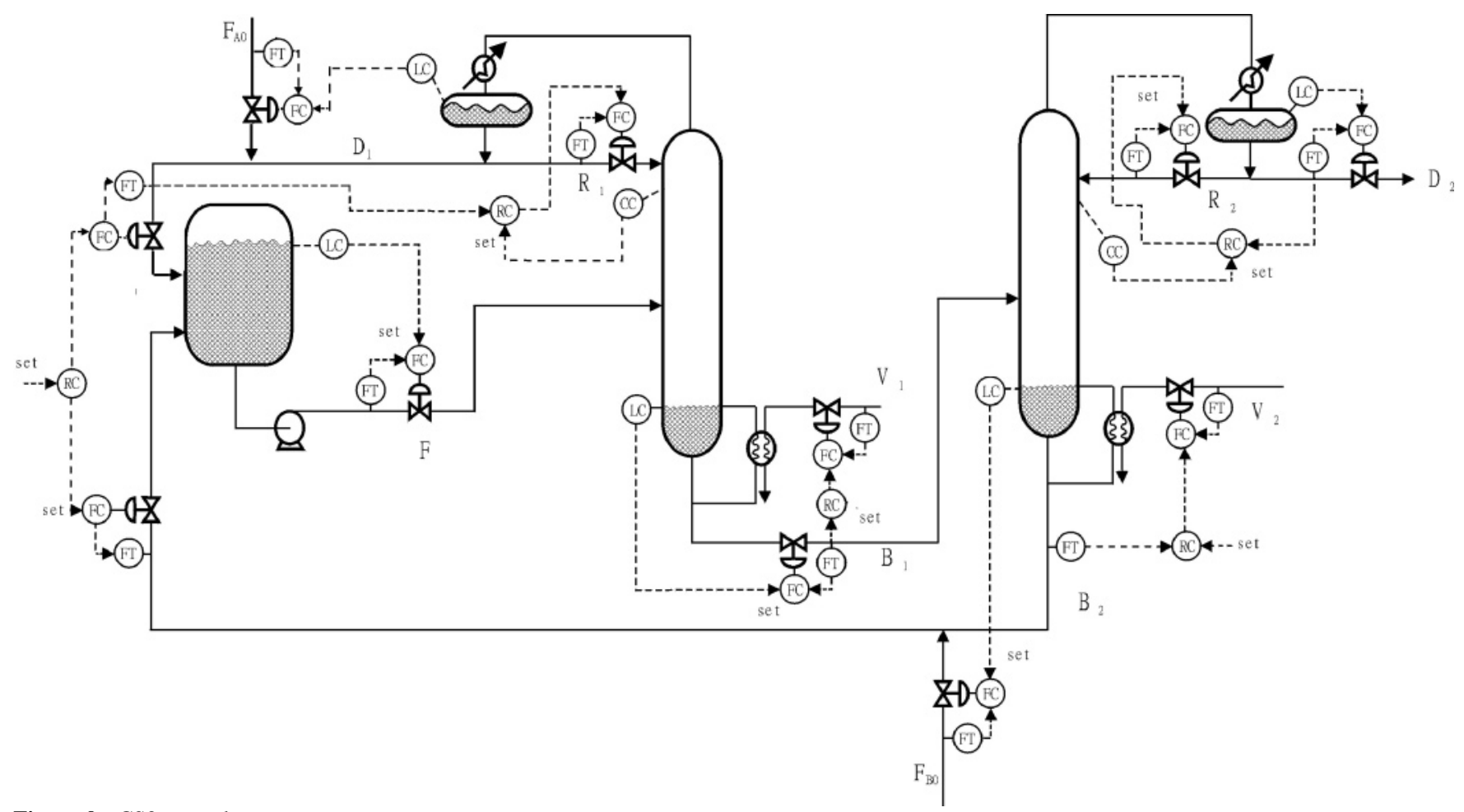

Figure 9. CS3 control structure.

singularity theory and bifurcation theory are proven tools, design application reports are relatively new. ${ }^{19-22}$ In recent years, Bildea and co-workers ${ }^{19,22,23}$ used bifurcation theory as a tool to analyze a reactor/separator recycle plant. Now, we will combine linear and nonlinear methods and use them to show which control structure can achieve preferable dynamics.

3.3.1. Nonlinearity. Bildea and Dimian ${ }^{23}$ conduct a nonlinear bifurcation analysis of a similar process. A portion of their analysis is briefly reviewed here, and the resulting bifurcation diagram (also produced by Bildea and Dimian) is reproduced. CS2A will be considered as an example.

A reactor material balance gives

$$
\begin{gathered}
F_{\mathrm{A} 0}+D_{1} x_{D 1, \mathrm{~A}}-F z_{\mathrm{A}}-k V_{\mathrm{R}} z_{\mathrm{A}} z_{\mathrm{B}}=0 \\
F_{\mathrm{B} 0}+B_{2} x_{B 2, \mathrm{~B}}-F z_{\mathrm{B}}-k V_{\mathrm{R}} z_{\mathrm{A}} z_{\mathrm{B}}=0
\end{gathered}
$$

For the distillation column material balance,

$$
\begin{gathered}
F_{\mathrm{A} 0}+F_{\mathrm{B} 0}+D_{1}+B_{2}-F=0 \\
F z_{\mathrm{A}}-D_{1} x_{D 1, \mathrm{~A}}=0 \\
F z_{\mathrm{B}}-B_{2} x_{B 2, \mathrm{~B}}=0
\end{gathered}
$$

For the control constraint,

$$
F_{\mathrm{B} 0}+B_{2}-F_{\mathrm{B}, \mathrm{in}}=0
$$

There are six equations (eqs 14-19) and six unknown variables $\left(F, D_{1}, B_{2}, F_{\mathrm{B} 0}, V_{\mathrm{R}}\right.$, and $\left.z_{\mathrm{B}}\right)$. The process variables $\left(x_{D 1, \mathrm{~A}}, x_{B 2, \mathrm{~B}}\right)$ are fixed by the system specifications. The feed flow rate $\left(F_{\mathrm{A} 0}\right)$ should be based on the production rate. The reaction rate constant is given by the kinetic data. For the given different conversion and recycle flow rate $\left(F_{\mathrm{B}, \text { in }}\right)$, the unknown variables can be solved using eqs 14-19. The results are shown in Figure 10 , and the bifurcation point can be found when the eigenvalue is equal to zero. The dashed line indicates that the process is operating in an unstable region. The center of the symmetrical curve is located at $z_{\mathrm{A}}=0.5$.
This result can also be understood intuitively, as follows: CS2 effectively maintains one recycle flow rate at a constant value by using a fresh feed flow rate as a makeup flow. Consider CS2A, where the fresh feed flow rate of species A is used to control the production rate, and the fresh feed flow rate of species $B$ is manipulated to maintain the recycle flow rate of species B at some predetermined ratio of the fresh feed flow rate of species $\mathrm{A}$. Consider the case where $z_{\mathrm{A}}<0.5$, and imagine a small disturbance which decreases the reaction rate (for example, a small decrease in the reactor temperature). The recycle flow rate of $\mathrm{B}$ is maintained constant, and the recycle flow rate of A increases until the overall reaction rate returns to the previous value. Thus, the system (with this control structure) is self-regulating. However, now consider the same control structure but the case where $z_{\mathrm{A}}>0.5$. If a small disturbance occurs that decreases the reaction rate, the recycle flow rate of A increases while the recycle flow rate of $\mathrm{B}$ remains constant. However, since species A is already in excess, the increased recycle flow rate further reduces the overall reaction rate, which in turn further increases the recycle flow rate of A. The situation gets progressively worse until the process becomes inoperable.

Now, the results can be translated into composition space. The stable and unstable regions can be observed more easily (see Figure 11). The operable range of CS2A is situated in the left-hand side of Figure 11.

3.3.2. Linear. In this section, we use linear analysis to investigate the stability and dynamics of CS2A and CS2B. Linear analysis will describe the local dynamic behavior of the process. However when the results are expressed in terms of design variables, linear analysis can be used to investigate global process dynamics.

Consider CS2B. Figure 8 shows the control structure. The throughput manipulated variable is the fresh feed of $\mathrm{B}\left(F_{\mathrm{B} 0}\right)$. The fresh feed of $\mathrm{A}\left(F_{\mathrm{A} 0}\right)$ is controlled by the recycling flow $\left(F_{\mathrm{A}}\right)$. It can be written as $F_{\mathrm{A} 0}=F_{\mathrm{A} \text {,in }}-F_{\mathrm{A}}$. Substituting the feedback relationship into eq 11 , we get

$$
F_{\mathrm{A}}=G_{\mathrm{P} 11}\left(F_{\mathrm{A}, \text { in }}-F_{\mathrm{A}}\right)+G_{\mathrm{P} 12} F_{\mathrm{B} 0}
$$




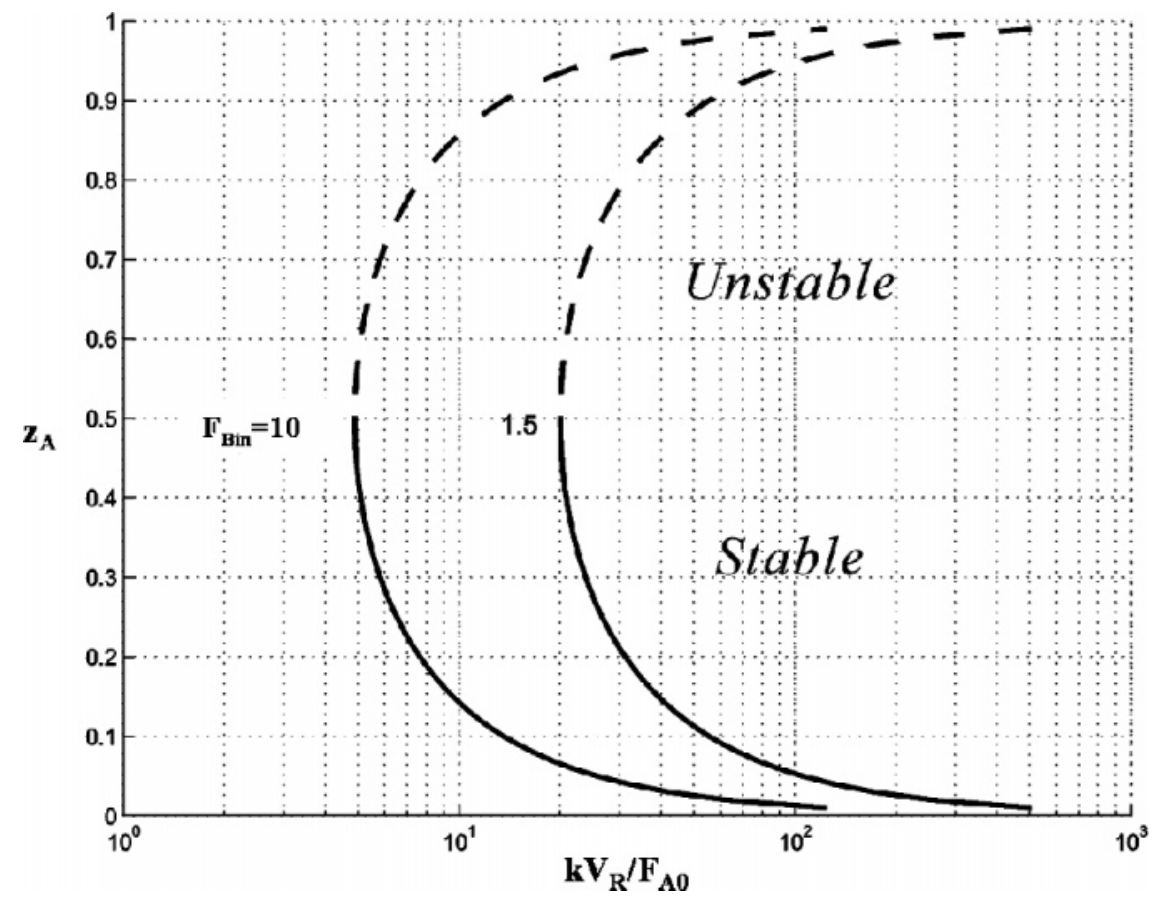

Figure 10. Bifurcation diagram under CS2A.

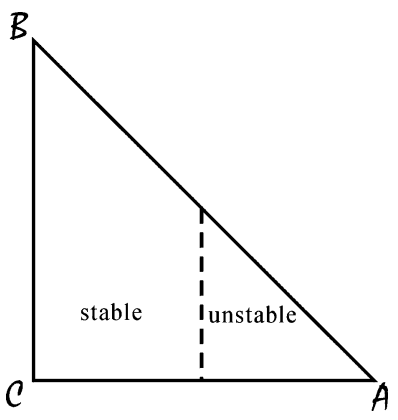

Figure 11. Stable operation area in the composition space for CS2A.

Rearranging eq 20, we have

$$
F_{\mathrm{A}}=\frac{G_{\mathrm{P} 11}}{1+G_{\mathrm{P} 11}} F_{\mathrm{A}, \mathrm{in}}+\frac{G_{\mathrm{P} 12}}{1+G_{\mathrm{P} 11}} F_{\mathrm{B} 0}=G_{\mathrm{PR} 1} F_{\mathrm{A}, \text { in }}+G_{\mathrm{PR} 2} F_{\mathrm{B} 0}
$$

Detailed derivations of $G_{\mathrm{PR} 1}$ and $G_{\mathrm{PR} 2}$ are shown in the Appendix. $G_{\mathrm{PR} 1}$ and $G_{\mathrm{PR} 2}$ do not include the integrator in the denominator of the transfer functions. This means that this control structure can eliminate the integrator from the recycling plant. And the feedback control structure (shown in Figure 8) will be stable if and only if $z_{\mathrm{C}}>0.5$ or $\lambda \leq 1 /\left(1-2 z_{\mathrm{C}}\right)$. Derivation of this result is in the Appendix.

In an analogous manner, for CS2A, we can write

$$
F_{\mathrm{B}}=\frac{G_{\mathrm{P} 22}}{1+G_{\mathrm{P} 22}} F_{\mathrm{B}, \text { in }}+\frac{G_{\mathrm{P} 21}}{1+G_{\mathrm{P} 22}} F_{\mathrm{A} 0}
$$

and by extending and rearranging eq 22, it can be shown in an analogous manner that the process will be stable if and only if $z_{\mathrm{C}}>0.5$ or $\lambda \leq 1-2 z_{\mathrm{C}}$.

The dashed line in Figure 11 shows the stability boundary. Further insight can be obtained with the aid of design-stage root locus diagrams. Consider CS2A. The denominator of the transfer function is a second-order polynomial. The two design variables $\left(\lambda, z_{\mathrm{C}}\right)$ vary from 0 to $\infty$ and from 0.2 to 0.8 , respectively. The poles of the transfer function can be calculated, and the results are shown in Figure 12. Figure 12 (parts A, B, and C) shows that, at different $z_{\mathrm{C}}$ values, the poles of the transfer function change with different reactant distribution. At $z_{\mathrm{C}}=0.2$, when the reactant distribution $(\lambda)$ changes from $\infty$ to 0 , the dominant pole of the transfer function passes through 0 and into the right half plane (RHP). The ultimate reactant distribution is located at $\lambda=0.6$ (see Figure $12 \mathrm{~A}$ ). Now we change the mole fraction of component $\mathrm{C}$ from 0.2 to 0.5 . When the reactant distribution $(\lambda)$ changes from $\infty$ to 0 , the dominant pole of the transfer function moves from the left half plane (LHP) and slowly decreases to 0 . The ultimate reactant distribution is located at $\lambda=0$ (see Figure 12B). The ultimate reactant distribution is a function of the $z_{\mathrm{C}}$ value. When $z_{\mathrm{C}}>0.5$, under CS2A, the unstable root disappears, and no matter how $\lambda$ changes, the system remains stable. The result is shown in Figure 12C. The same approach can be used to analyze CS2B, with analogous results.

3.4. Implementation and Dynamic Responses. Here, the pole location provides us with information for the control structure selection. If the value of $\lambda$ in CS2A is small, the pole of the system approaches 0 or RHP. This means that the dynamics will become slow or unstable. When $\lambda$ is large, we should select CS2A to obtain a quicker dynamic response. When $\lambda$ is small, we should select CS2B to obtain a quicker dynamic response.

Having performed nonlinear analysis, we understand the stability and operability in the composition space for a ternary system with recycle. Now we use the linear transfer function model and look at the dynamic response for the local steady state operating point. Figure 13 shows four operating points, together with the stability boundaries calculated in Section 3.3. The four points separately fall in four different regions. We performed the dynamic simulation for these four steady-state design points using CS2A and CS2B. In all cases, an analyzer dead time of 4 min is assumed and the composition loop is tuned with relay feedback tests ${ }^{29}$ followed by Tyreus-Luyben settings ${ }^{30}$ for proportional-integral (PI) controllers.

Figure 14 shows the dynamic response for design point $\mathrm{A}$. In CS2A, we made a $1 \%$ step change in the feed rate $\left(F_{\mathrm{A} 0}\right)$. The system diverges immediately. However, in CS2B, the system could be stabilized. Thus, we can use CS2B in this design 

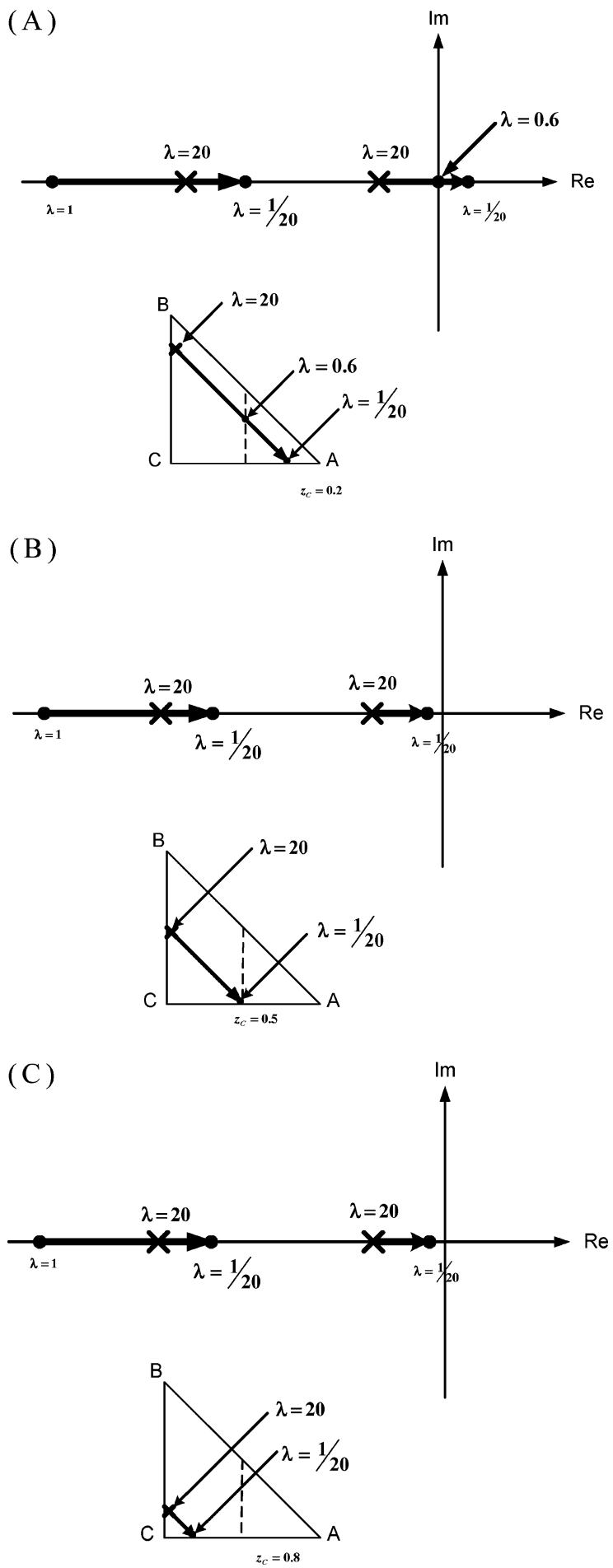

Figure 12. Design-stage root locus plot of CS2A, (A) $z_{\mathrm{C}}=0.2$, (B) $z_{\mathrm{C}}=$ 0.5 , and $(\mathrm{C}) z_{\mathrm{C}}=0.8$

region (point A). This result is consistent with previous analysis. Figure 15 shows the dynamic response of design point $\mathrm{B}$ using $\mathrm{CS} 2 \mathrm{~A}$ and $\mathrm{CS} 2 \mathrm{~B}$. Both of the control structures handle the system well, but the dynamic response of CS2A is excessively slow. Thus, in this design region, CS2B is suitable. This result is also consistent with the nonlinear analysis. From Figures 16 and 17 , respectively, it is clear that design points $\mathrm{C}$ and $\mathrm{D}$ should use CS2A.

With CS3, the production rate cannot be set explicitly by adjusting a fresh feed flow rate. However, it can be adjusted implicitly by manipulating the recycle flow rates, as shown in Figure 18. If the recycle flow rates are equal, for example, point

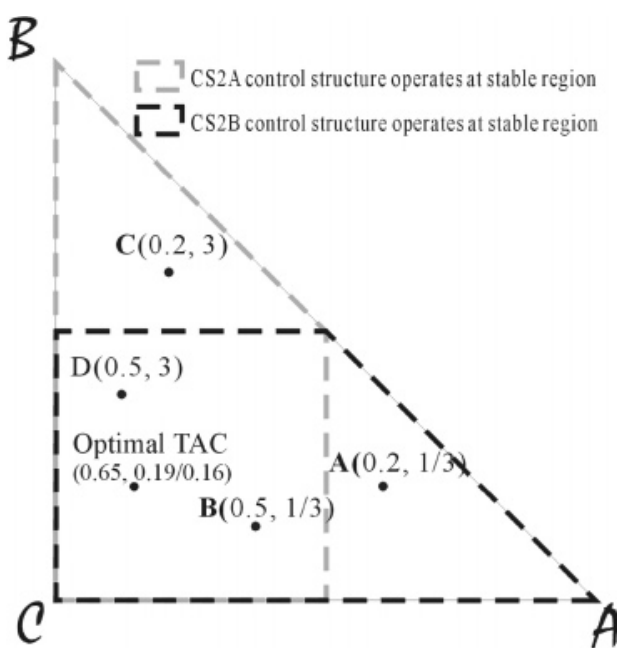

Figure 13. Suitable control structures drawn in the composition space The black dashed area uses CS2B control structure to maintain the system at the stable region. The gray dashed area uses CS2A control structure to maintain the system at the stable region. The different design points $\mathrm{A}-\mathrm{D}$ are shown in the figure and have coordinates $\left(z_{\mathrm{C}}, \lambda\right)$.
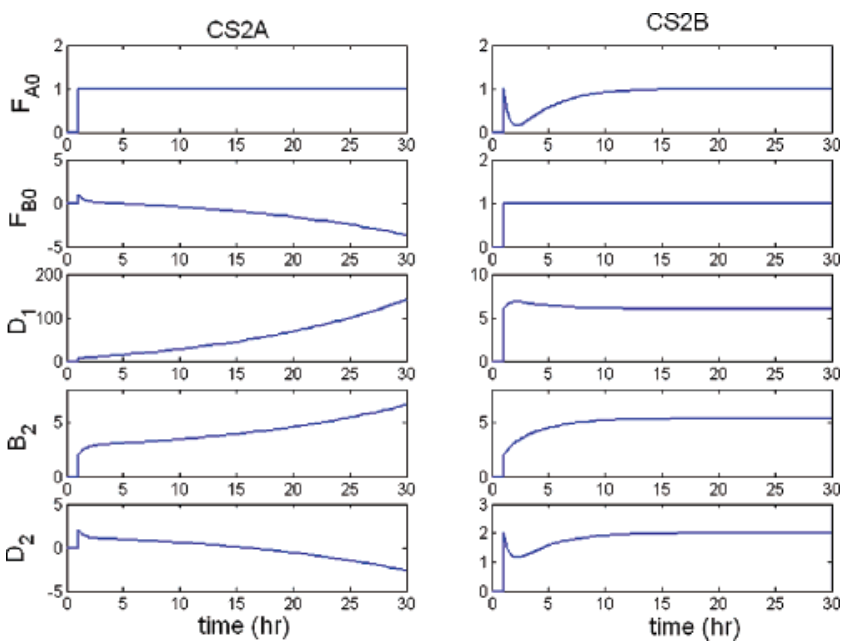

Figure 14. Dynamic responses of the steady-state design point (Figure 16 , point $\mathrm{A}, z_{\mathrm{A}}=0.6, z_{\mathrm{B}}=0.2$, and $z_{\mathrm{C}}=0.2$ ).
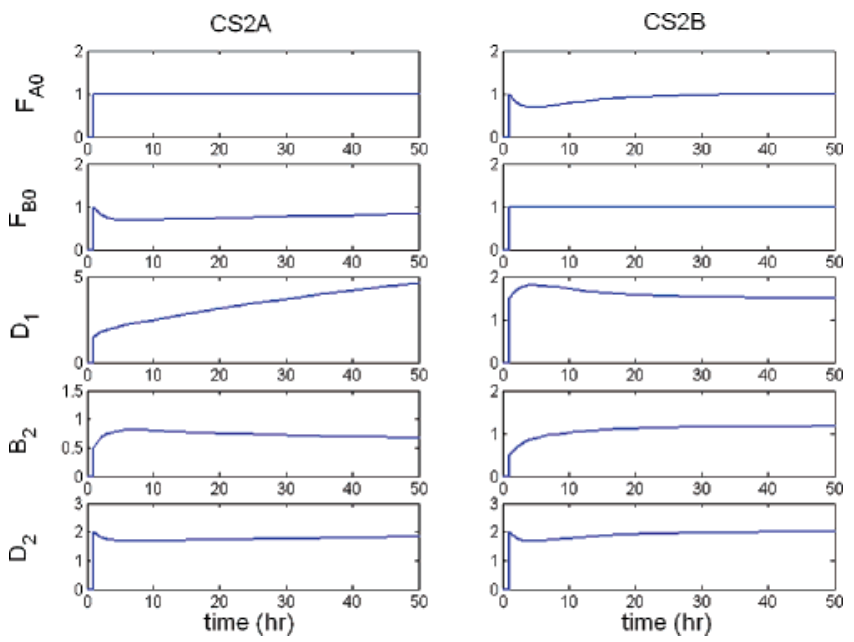

Figure 15. Dynamic responses of the steady-state design point (Figure 16 , point $\mathrm{B}, z_{\mathrm{A}}=0.375, z_{\mathrm{B}}=0.125$, and $z_{\mathrm{C}}=0.5$ ).

A in Figure 18, then the production rate can be increased by increasing both of the recycle flow rates. This corresponds to moving from point $\mathrm{A}$ to point $\mathrm{C}$ in Figure 18.

If the recycle flow rates are unequal, for example, point $\mathrm{B}$ in Figure 18, then the production rate can be increased by adjusting 

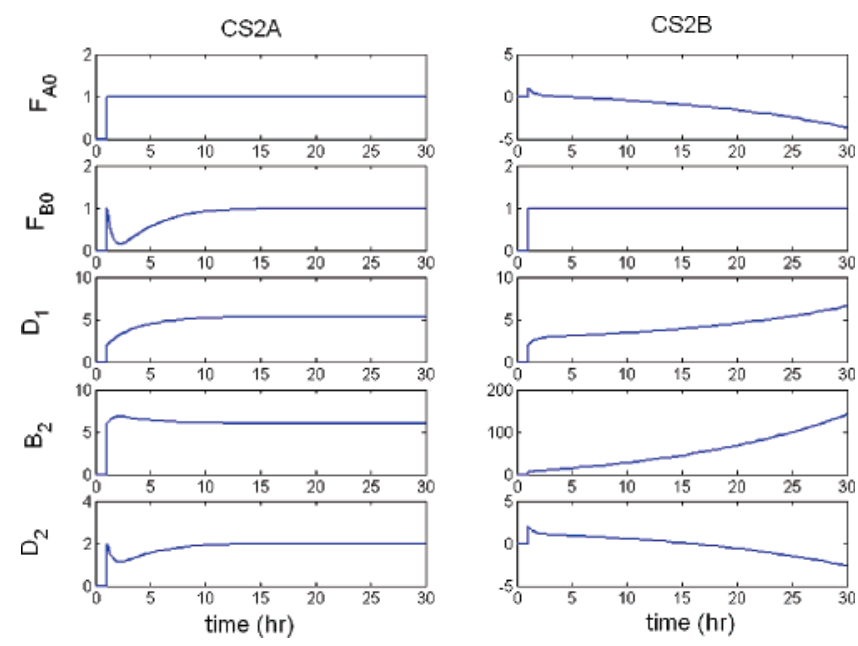

Figure 16. Dynamic responses of the steady-state design point (Figure 16 , point $\mathrm{C}, z_{\mathrm{A}}=0.2, z_{\mathrm{B}}=0.6$, and $z_{\mathrm{C}}=0.2$ ).
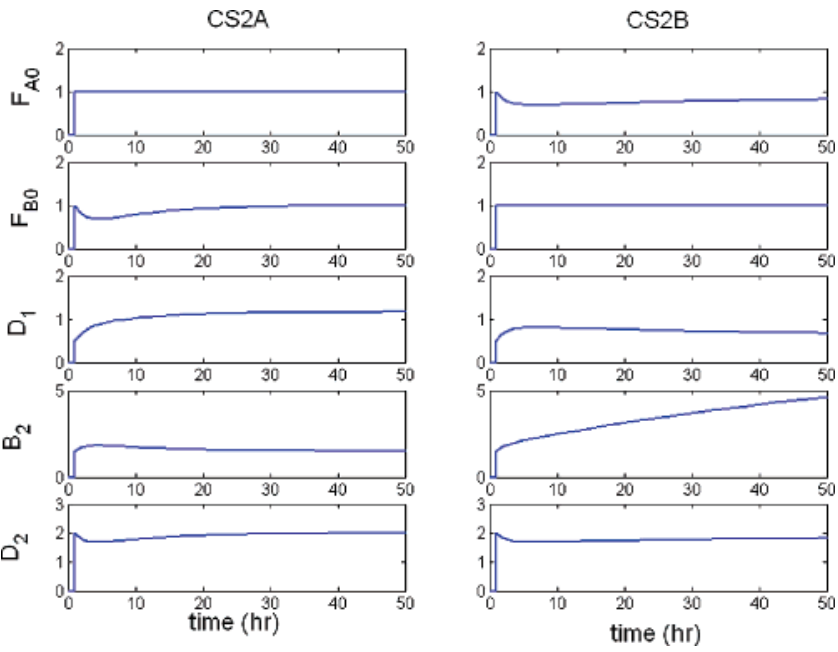

Figure 17. Dynamic responses of the steady-state design point (Figure 16 , point $\mathrm{D}, z_{\mathrm{A}}=0.125, z_{\mathrm{B}}=0.375$, and $z_{\mathrm{C}}=0.5$ ).

the recycle flow rates so that they are equal. This corresponds to moving from point $\mathrm{B}$ to point $\mathrm{A}$ on the diagram.
We will give an example from Cheng and $\mathrm{Yu}^{27}$ to illustrate a suitable control structure. For a case study that they developed, they found that the optimal total annual cost (TAC) (as defined by Douglas ${ }^{28}$ ) was located at $z_{\mathrm{A}}=0.16, z_{\mathrm{B}}=0.19$, and $z_{\mathrm{C}}=$ 0.65 in the composition space. At this design point (from Figure 13), we can eliminate CS2B. The candidate control structures are CS2A and CS3. We can make a $1 \%$ step change in the production rate. As shown in Figure 19, the dynamic response of CS3 is faster than that of CS2A. According to the dynamic behavior, CS3 is a better choice.

3.5. Procedure and Results. Here, we summarize the results from Section 3. We will propose a systematic procedure for selecting a control structure for different values of design parameters. The steps can be briefly summarized as follows:

(1) Identify promising control structures.

(2) Eliminate unworkable control structures to avoid instability.

(3) Eliminate unworkable control structures to avoid limited operability.

(4) Select preferable dynamics.

(5) Determine the control structure for the design point.

This procedure can generate the preferable control structure for different steady-state design regions. In our example, we find three candidate control structures that can be used for control of a ternary recycling process. For CS1, the degree-offreedom analysis cannot be satisfied. Therefore, we eliminate CS1. The remaining control structures are CS2A, CS2B, and CS3. From nonlinear and linear analysis, we can decide which control structure should be used. With CS2, the throughput can be adjusted explicitly. CS3 gives better dynamics performance under certain steady-state designs, but the throughput cannot be adjusted explicitly. This means that, if we want to increase the production rate, the fresh feed $\left(F_{\mathrm{A} 0}\right.$ and $\left.F_{\mathrm{B} 0}\right)$ cannot be adjusted directly to achieve the change. So, we choose CS2 as our final control structure.

\section{Control System Design}

4.1. Ratio Control. From a combination of linear and nonlinear analysis, we know that, if we make a step change in the fresh feed, the throughput will change immediately. We will

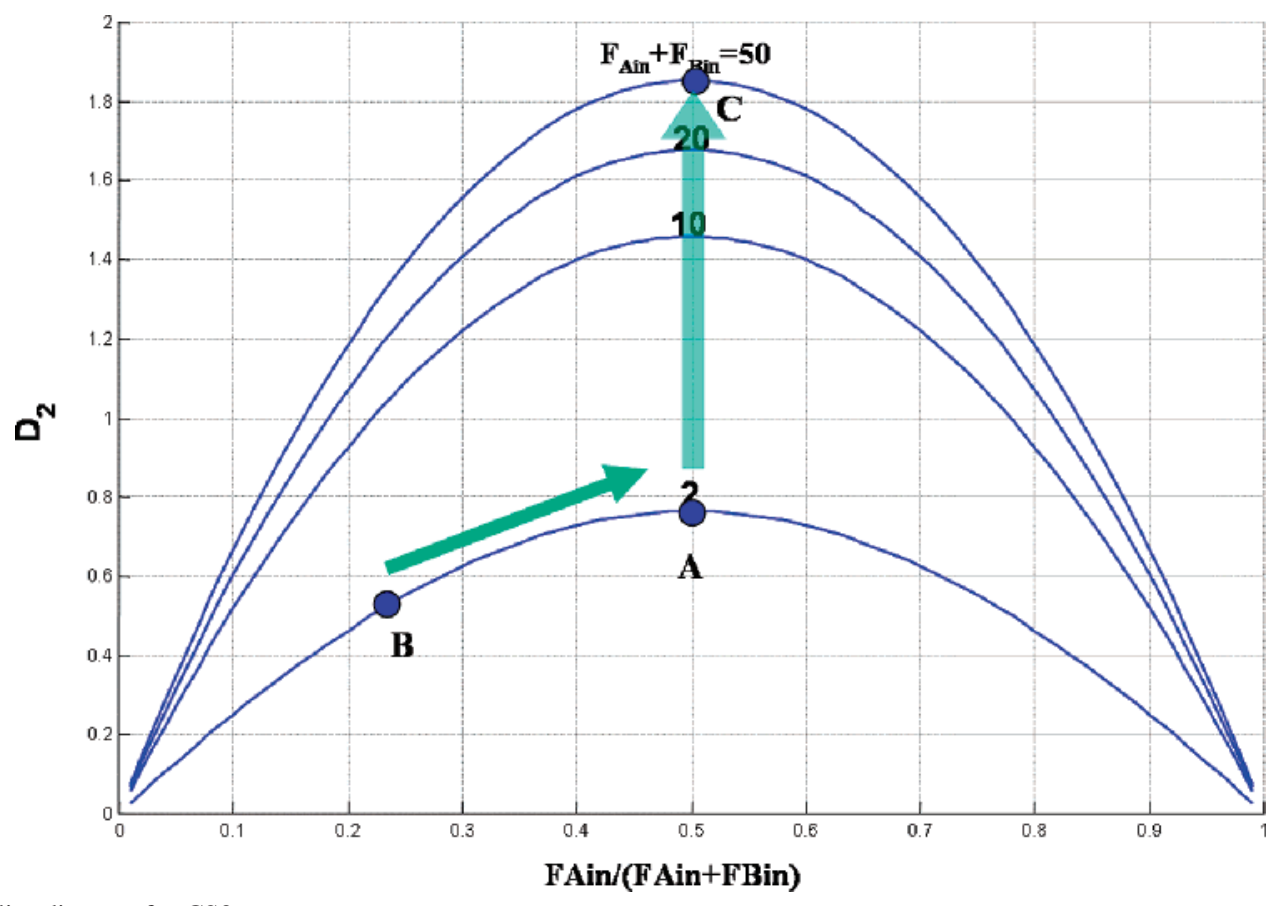

Figure 18. Operability diagram for CS3. 

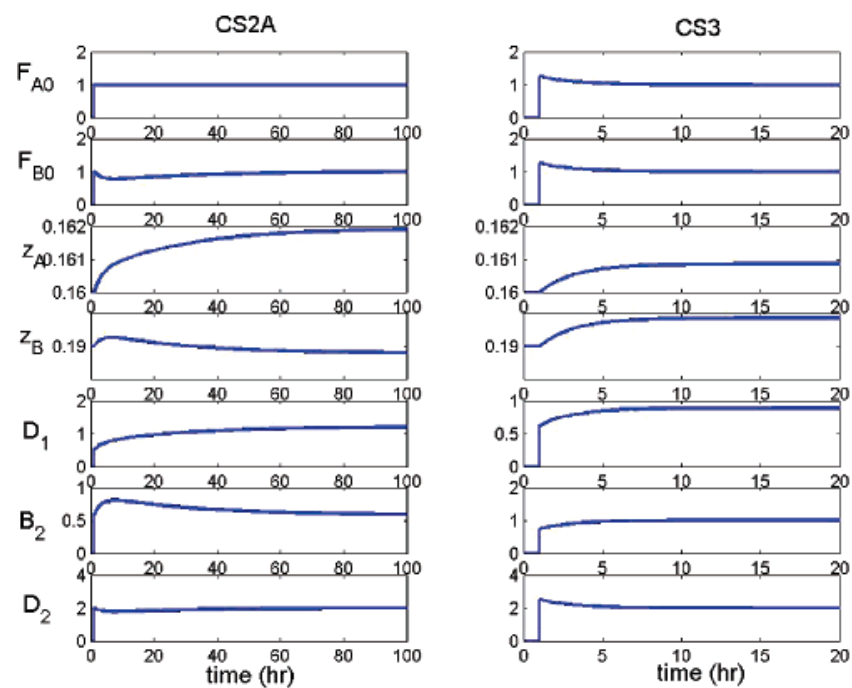

Figure 19. Comparison of the dynamic response of CS2A and CS3 at optimal TAC design point $\left(z_{\mathrm{A}}=0.16, z_{\mathrm{B}}=0.19\right.$, and $\left.z_{\mathrm{C}}=0.65\right)$.
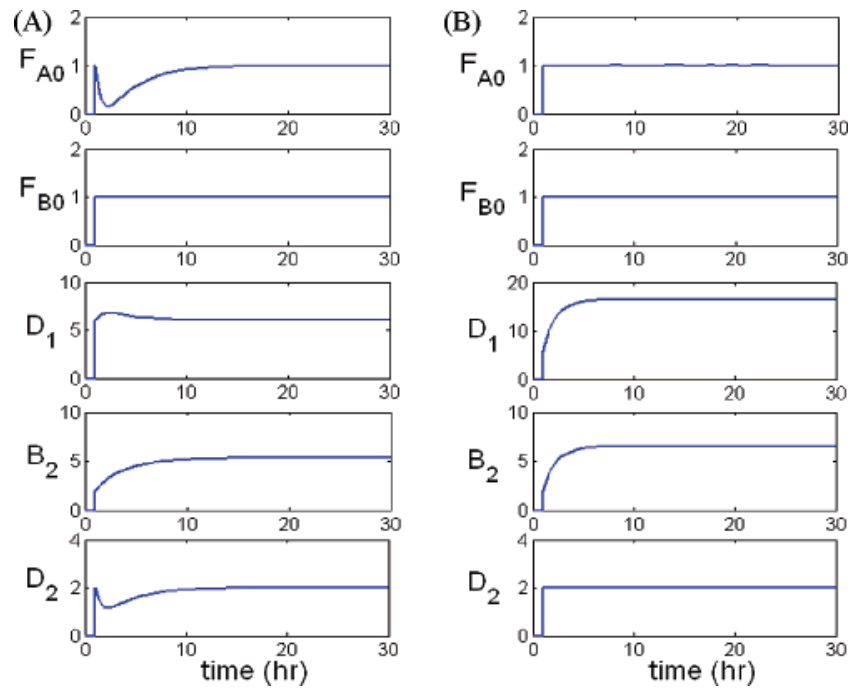

Figure 20. Dynamic responses for CS2B: (A) ratio control with constant gain and $(B)$ ratio control with dynamics.

take $\mathrm{CS} 2 \mathrm{~B}$ as an example. When $F_{\mathrm{A} 0}$ and $F_{\mathrm{B} 0}$ are subjected to a step change simultaneously, the product $F_{\mathrm{C}}$ will change immediately in the outlet stream. In CS2B, we take $F_{\mathrm{B} 0}$ as a throughput manipulated variable. $F_{\mathrm{A} \text {,in }}$ and $F_{\mathrm{B} 0}$ maintain a fixed ratio. The ratio should be fixed at a steady-state value $\left(F_{\mathrm{A} \text {,in }} / F_{\mathrm{B} 0}\right)$.

4.2. Linear Ratio Control. Here, we will use the result mentioned in Section 2 concerning the relationship of the transfer function $\left(F_{\mathrm{A} \text {,in }} / F_{\mathrm{B} 0}\right)$. We can derive

$$
\begin{gathered}
F_{\mathrm{A}}=\left(G_{\mathrm{P} 11}+G_{\mathrm{P} 12}\right) F_{\mathrm{B} 0} \\
F_{\mathrm{A}}+F_{\mathrm{A} 0}=F_{\mathrm{A}, \mathrm{in}}=\left(G_{\mathrm{P} 11}+G_{\mathrm{P} 12}+1\right) F_{\mathrm{B} 0}
\end{gathered}
$$

We can see that, to achieve perfect production rate control, the $F_{\mathrm{A}, \text { in }} / F_{\mathrm{B} 0}$ value should not be a fixed value. It should be a dynamic value, that is, $F_{\mathrm{A}, \mathrm{in} /} F_{\mathrm{B} 0}=G_{\mathrm{P} 11}(\mathrm{~s})+G_{\mathrm{P} 12}(\mathrm{~s})+1$. We may introduce this dynamic transfer function to the ratio control. As expected, we can achieve perfect production rate control.

We compare the dynamic response of fixed ratio control and dynamic ratio control. Figure 20A shows the dynamic response of CS2B when the $F_{\mathrm{A}, \text { in }} / F_{\mathrm{B} 0}$ ratio remains constant. The steadystate design point is located at point A in Figure 16 using CS2B. The steady-state conditions of the process are listed in Table 4. Figure 20A shows the dynamic response of CS2B, which was

\begin{tabular}{|c|c|c|c|}
\hline & $z_{\mathrm{C}}=0.2$ & $z_{\mathrm{C}}=0.5$ & $z_{\mathrm{C}}=0.8$ \\
\hline \multicolumn{4}{|c|}{ CSTR } \\
\hline reactants distribution $\left(z_{\mathrm{B}} / z_{\mathrm{A}}\right)$ & 1 & 1 & 1 \\
\hline reaction rate constant $(k)$ & 1 & 1 & 1 \\
\hline fresh feed flow rate $\mathrm{A}\left(F_{\mathrm{A} 0}\right)(\mathrm{lbmol} / \mathrm{h})$ & 100 & 100 & 100 \\
\hline fresh feed flow rate $\mathrm{B}\left(F_{\mathrm{B} 0}\right)(\mathrm{lbmol} / \mathrm{h})$ & 100 & 100 & 100 \\
\hline Recycle flow rate $\left(D_{1}\right)(\mathrm{lbmol} / \mathrm{h})$ & 410.53 & 97.96 & 22.79 \\
\hline recycle stream composition $\left(x_{D 1, \mathrm{~A}}\right)$ & 0.99 & 0.99 & 0.99 \\
\hline recycle stream composition $\left(x_{D 1, \mathrm{~B}}\right)$ & 0.00 & 0.00 & 0.00 \\
\hline recycle stream composition $\left(x_{D 1, \mathrm{C}}\right)$ & 0.01 & 0.01 & 0.01 \\
\hline recycle flow rate $\left(B_{2}\right)(1 \mathrm{bmol} / \mathrm{h})$ & 410.53 & 97.96 & 22.79 \\
\hline recycle stream composition $\left(x_{B 2, \mathrm{~A}}\right)$ & 0.00 & 0.00 & 0.00 \\
\hline recycle stream composition $\left(x_{B 2, \mathrm{~B}}\right)$ & 0.99 & 0.99 & 0.99 \\
\hline recycle stream composition $\left(x_{B 2, C}\right)$ & 0.01 & 0.01 & 0.01 \\
\hline reactor holdup $\left(V_{\mathrm{R}}\right)(\mathrm{lbmol})$ & 612.5 & 1568 & 9800 \\
\hline \multicolumn{4}{|c|}{ Distillation Column 1} \\
\hline column feed flow rate $(F)(\mathrm{lbmol} / \mathrm{h})$ & 1021.05 & 395.92 & 245.57 \\
\hline bottom flow rate $\left(B_{1}\right)(\mathrm{lbmol} / \mathrm{h})$ & 610.53 & 297.96 & 222.78 \\
\hline vapor boilup $\left(V_{1}\right)(\mathrm{lbmol} / \mathrm{h})$ & 1312.97 & 471.93 & 277.50 \\
\hline reflux flow rate $\left(R_{1}\right)(1 \mathrm{bmol} / \mathrm{h})$ & 2.20 & 3.82 & 11.18 \\
\hline no. of trays $\left(N_{\mathrm{T}}\right)$ & 27 & 27 & 27 \\
\hline feed tray $\left(N_{\mathrm{F}}\right)$ & 18 & 14 & 10 \\
\hline liquid hydraulic time constant $(\beta)(\mathrm{s})$ & 5.94 & 4.12 & 3.39 \\
\hline reflux drum holdup $\left(M_{\mathrm{D}}\right)$ (lbmol/tray) & 109.41 & 39.33 & 23.12 \\
\hline tray holdup $\left(M_{\mathrm{N}}\right)(\mathrm{lbmol} /$ tray $)$ & 6.30 & 2.03 & 1.14 \\
\hline bottom holdup $\left(M_{\mathrm{B}}\right)(\mathrm{lbmol} /$ tray $)$ & 160.29 & 64.16 & 41.69 \\
\hline \multicolumn{4}{|c|}{ Distillation Column 2} \\
\hline distillate flow rate $\left(D_{2}\right)(\mathrm{lbmol} / \mathrm{h})$ & 200 & 200 & 200 \\
\hline distillate stream composition $\left(x_{D 2, \mathrm{~A}}\right)$ & 0.01 & 0.01 & 0.01 \\
\hline distillate stream composition $\left(x_{D 2, \mathrm{~B}}\right)$ & 0.01 & 0.01 & 0.01 \\
\hline distillate stream composition $\left(x_{D 2, \mathrm{C}}\right)$ & 0.98 & 0.98 & 0.98 \\
\hline vapor boilup $\left(V_{2}\right)(\mathrm{lbmol} / \mathrm{h})$ & 908.71 & 573.93 & 452.22 \\
\hline reflux flow rate $\left(R_{2}\right)(\mathrm{lbmol} / \mathrm{h})$ & 3.54 & 1.87 & 1.26 \\
\hline no. of trays $\left(N_{\mathrm{T}}\right)$ & 27 & 27 & 27 \\
\hline feed tray $\left(N_{\mathrm{F}}\right)$ & 13 & 17 & 21 \\
\hline liquid hydraulic time constant $(\beta)(\mathrm{s})$ & 5.52 & 5.16 & 4.85 \\
\hline reflux drum holdup $\left(M_{\mathrm{D}}\right)(\mathrm{lbmol} /$ tray $)$ & 75.73 & 47.83 & 37.68 \\
\hline tray holdup $\left(M_{\mathrm{N}}\right)(\mathrm{lbmol} /$ tray $)$ & 4.01 & 2.29 & 1.75 \\
\hline bottom holdup $\left(M_{\mathrm{B}}\right)(\mathrm{lbmol} / \mathrm{tray})$ & 109.94 & 55.99 & 39.58 \\
\hline
\end{tabular}

Table 4. Steady-State Conditions for the Plant with Recycle ${ }^{a}$

determined in earlier analysis to be the best control structure. When $F_{\mathrm{B} 0}$ undergoes a step change, the production rate will not be perfectly controlled. The production rate increases and then decreases. Figure 20B shows the response with dynamic ratio control. Here, the same steady-state operation point is used. When $F_{\mathrm{B} 0}$ undergoes a step change, perfect production rate control can be achieved.

\section{Conclusion}

In this paper, we have discussed a simple system with recycle. A linear model for the ternary recycling process was established. From transfer function analysis, we can clearly understand the influence of the design variables on the system dynamics. Therefore, we can draw two conclusions: First, the internal flow of the ternary recycled process has an unstable characteristic (an integrating pole). The process is stable only when the fresh feed flow rates are exactly balanced. Therefore, we need to use internal measurements to adjust at least one fresh feed flow rate. Second, it is possible to achieve perfect production rate control for this process with recycle for any operation condition.

We have examined several controls structures (CS1, CS2A, CS2B, and CS3). CS1 feed-forward control cannot be used because of violation of the degree-of-freedom analysis. We use linear and nonlinear analysis to investigate the other control structures. Nonlinear analysis provided us a global viewpoint to discuss stability and operability with the different steadystate designs. It also lets us choose the control structure for different design regions. Then, ratio control is used to improve the control performance. Finally, we used a rigorous model to validate the results. 


\section{Acknowledgment}

This work was supported by the National Science Council of Taiwan.

\section{Appendix: Derivation of Closed-Loop Transfer Functions and Stability Analysis for CS2B}

From eq 11 , we have the $g_{\mathrm{P} 11}$ and $g_{\mathrm{P} 12}$ transfer function,

$$
\begin{gathered}
g_{\mathrm{P} 11}=\frac{1-z_{\mathrm{C}}\left[s^{2}+\frac{k\left(1-z_{\mathrm{C}}\right)\left(2 \lambda z_{\mathrm{C}}+3 \lambda^{2} z_{\mathrm{C}}+z_{\mathrm{C}}+2 \lambda\right)}{z_{\mathrm{C}}(1+\lambda)^{2}} s+\frac{2 \lambda k^{2}\left(1-z_{\mathrm{C}}\right)^{2}\left(1-\lambda\left(1-2 z_{\mathrm{C}}\right)\right)}{z_{\mathrm{C}}(1+\lambda)^{3}}\right]}{s\left(s+k\left(1-z_{\mathrm{C}}\right)\right)} \\
g_{\mathrm{P} 12}=\frac{1-z_{\mathrm{C}}\left[s^{2}+\frac{k\left(1-z_{\mathrm{C}}\right)\left(z_{\mathrm{C}}+\lambda^{2} z_{\mathrm{C}}+2 \lambda\right)}{z_{\mathrm{C}}(1+\lambda)} s-\frac{2 \lambda k^{2}\left(1-z_{\mathrm{C}}\right)^{2}\left(1-\lambda\left(1-2 z_{\mathrm{C}}\right)\right)}{z_{\mathrm{C}}(1+\lambda)^{3}}\right]}{s\left(s+k\left(1-z_{\mathrm{C}}\right)\right)}
\end{gathered}
$$

The feedback control structure is shown in Figure $8 \mathrm{~B}$. The throughput manipulated variable is the fresh feed of $\mathrm{B}\left(F_{\mathrm{B} 0}\right)$. The fresh feed of $\mathrm{A}\left(F_{\mathrm{A} 0}\right)$ is controlled by the recycling flow $\left(F_{\mathrm{A}}\right)$. It can be written as $F_{\mathrm{A} 0}=F_{\mathrm{A}, \text { in }}-F_{\mathrm{A}}$. Let $p=k\left(1-z_{\mathrm{C}}\right)$ Substituting the feedback relationship into eq 16 and rearranging it, we have

$$
\begin{aligned}
& F_{\mathrm{A}}(s)=\frac{G_{\mathrm{P} 11}}{1+G_{\mathrm{P} 11}} F_{\mathrm{A}, \mathrm{in}}(s)+\frac{G_{\mathrm{P} 12}}{1+G_{\mathrm{P} 11}} F_{\mathrm{B} 0}(s)=G_{\mathrm{PR} 1} F_{\mathrm{A}, \text { in }}(s)+G_{\mathrm{PR} 2} F_{\mathrm{B} 0}(s) \\
& 1-z_{\mathrm{C}}\left[s^{2}+\frac{p\left(2 \lambda z_{\mathrm{C}}+3 \lambda^{2} z_{\mathrm{C}}+z_{\mathrm{C}}+2 \lambda\right)}{z_{\mathrm{C}}(1+\lambda)^{2}} s+\frac{2 \lambda p^{2}\left(1-\lambda\left(1-2 z_{\mathrm{C}}\right)\right)}{z_{\mathrm{C}}(1+\lambda)^{3}}\right]
\end{aligned}
$$

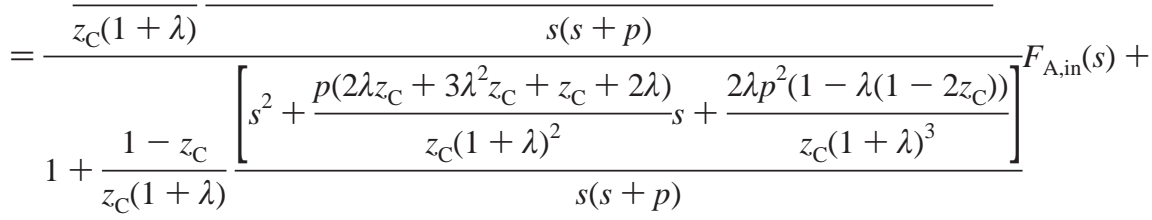

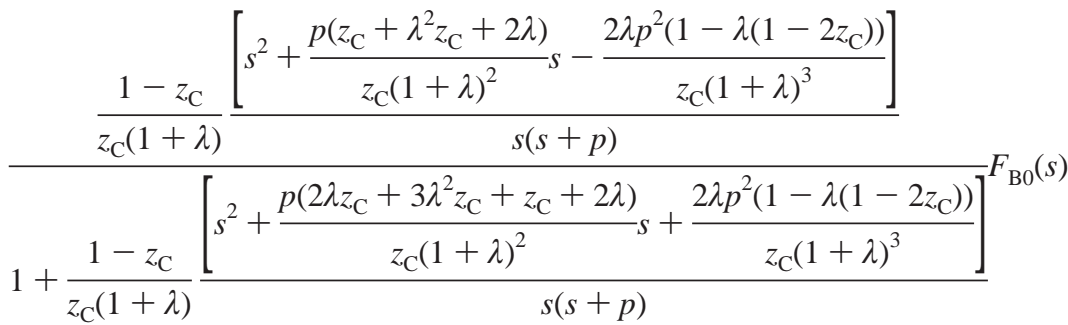

$$
\begin{aligned}
& =\frac{\left[s^{2}+\frac{p\left(2 \lambda z_{\mathrm{C}}+3 \lambda^{2} z_{\mathrm{C}}+z_{\mathrm{C}}+2 \lambda\right)}{z_{\mathrm{C}}(1+\lambda)^{2}} s+\frac{2 \lambda p^{2}\left(1-\lambda\left(1-2 z_{\mathrm{C}}\right)\right)}{z_{\mathrm{C}}(1+\lambda)^{3}}\right]}{\frac{z_{\mathrm{C}}(1+\lambda)}{1-z_{\mathrm{C}}} s^{2}+\frac{z_{\mathrm{C}}(1+\lambda) p}{1-z_{\mathrm{C}}} s+\left[s^{2}+\frac{p\left(2 \lambda z_{\mathrm{C}}+3 \lambda^{2} z_{\mathrm{C}}+z_{\mathrm{C}}+2 \lambda\right)}{z_{\mathrm{C}}(1+\lambda)^{2}} s+\frac{2 \lambda p^{2}\left(1-\lambda\left(1-2 z_{\mathrm{C}}\right)\right)}{z_{\mathrm{C}}(1+\lambda)^{3}}\right]} F_{\mathrm{A}, \text { in }}(s)+ \\
& {\left[s^{2}+\frac{p\left(z_{\mathrm{C}}+\lambda^{2} z_{\mathrm{C}}+2 \lambda\right)}{z_{\mathrm{C}}(1+\lambda)^{2}} s+\frac{2 \lambda p^{2}\left(1-\lambda\left(1-2 z_{\mathrm{C}}\right)\right)}{z_{\mathrm{C}}(1+\lambda)^{3}}\right]} \\
& \frac{z_{\mathrm{C}}(1+\lambda)^{2}}{\frac{z_{\mathrm{C}}(1+\lambda)}{1-z_{\mathrm{C}}} s^{2}+\frac{z_{\mathrm{C}}(1+\lambda) p}{1-z_{\mathrm{C}}} s+\left[s^{2}+\frac{p\left(2 \lambda z_{\mathrm{C}}+3 \lambda^{2} z_{\mathrm{C}}+z_{\mathrm{C}}+2 \lambda\right)}{z_{\mathrm{C}}(1+\lambda)^{2}} s+\frac{2 \lambda p^{2}\left(1-\lambda\left(1-2 z_{\mathrm{C}}\right)\right)}{z_{\mathrm{C}}(1+\lambda)^{3}}\right]} F_{\mathrm{B} 0}(s)
\end{aligned}
$$

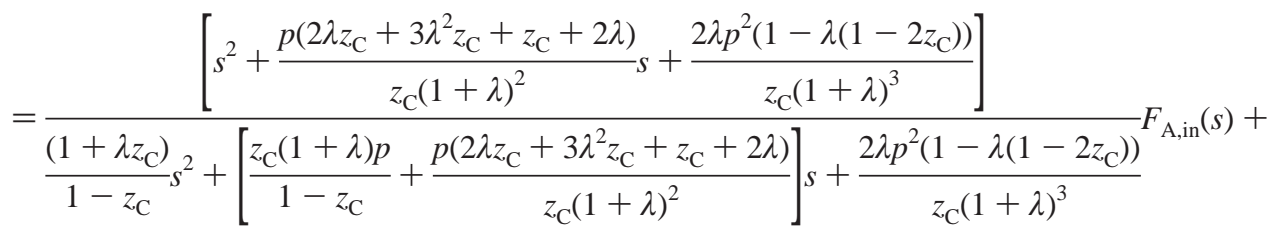

$$
\begin{aligned}
& {\left[s^{2}+\frac{p\left(z_{\mathrm{C}}+\lambda^{2} z_{\mathrm{C}}+2 \lambda\right)}{z_{\mathrm{C}}(1+\lambda)^{2}} s+\frac{2 \lambda p^{2}\left(1-\lambda\left(1-2 z_{\mathrm{C}}\right)\right)}{z_{\mathrm{C}}(1+\lambda)^{3}}\right]} \\
& \frac{\left(1+\lambda z_{\mathrm{C}}\right)}{\frac{z_{\mathrm{C}}}{1-z_{\mathrm{C}}} s^{2}+\left[\frac{z_{\mathrm{C}}(1+\lambda) p}{1-z_{\mathrm{C}}}+\frac{p\left(2 \lambda z_{\mathrm{C}}+3 \lambda^{2} z_{\mathrm{C}}+z_{\mathrm{C}}+2 \lambda\right)}{z_{\mathrm{C}}(1+\lambda)^{2}}\right] s+\frac{2 \lambda p^{2}\left(1-\lambda\left(1-2 z_{\mathrm{C}}\right)\right)}{z_{\mathrm{C}}(1+\lambda)^{3}}} F_{\mathrm{B} 0}(s)
\end{aligned}
$$


By application of the Routh stability criterion $^{30}$ to a secondorder system, the process will be stable if and only if all three coefficients in the denominator are positive. The first and second coefficients are always positive for any value of $z_{\mathrm{C}}$ and $\lambda\left(z_{\mathrm{B}} /\right.$ $\left.z_{\mathrm{A}}\right)$. The constant term will be positive if and only if $(1-\lambda(1$ $\left.\left.-2 z_{\mathrm{C}}\right)\right)>0$. Therefore, for stability, $\lambda$ must be less than or equal to $1 /\left(1-2 z_{\mathrm{C}}\right)$ if $z_{\mathrm{C}}<0.5$. If $z_{\mathrm{C}}>0.5$, the system is always stable.

\section{Nomenclature}

$\mathrm{A}=$ reactant

$\mathrm{B}=$ reactant

$B_{i}=$ bottom flow rate from the $i$ th column

$\mathrm{C}=$ product

$\mathrm{CS} 1=$ feedforward control structure

$\mathrm{CS} 2 \mathrm{~A}=$ feedback control structure with a fixed recycle flow rate $D_{1}$

$\mathrm{CS} 2 \mathrm{~B}=$ feedback control structure with a fixed recycle flow rate $B_{2}$

$\mathrm{CS} 3=$ feedback control structure with a fixed recycle flow rates $D_{1}$ and $B_{2}$

$D a=$ Damkolher number

$D_{i}=$ distillate flow rate from the $i$ th column $(\mathrm{lbmol} / \mathrm{hr})$

$F=$ reactor effluent flow rate $(\mathrm{lbmol} / \mathrm{hr})$

$\bar{F}=$ nominal value of the reactor effluent flow rate $(\mathrm{lbmol} / \mathrm{hr})$

$F_{\mathrm{A}}=$ total flow rate of reactant A $(\mathrm{lbmol} / \mathrm{hr})$

$\bar{F}_{A}=$ nominal value of the total flow rate of reactant A (lbmol/ $\mathrm{hr})$

$F_{\mathrm{A} \text {,in }}=$ reactor inlet flow rate of the reactant $\mathrm{A}(\mathrm{lbmol} / \mathrm{hr})$

$\bar{F}_{\mathrm{A} \text {,in }}=$ nominal value of the total reactor inlet flow rate of reactant A (lbmol/hr)

$F_{\mathrm{A} 0}=$ fresh feed flow rate of component $\mathrm{A}(\mathrm{lbmol} / \mathrm{hr})$

$F_{\mathrm{B}}=$ total flow rate of reactant B $(\mathrm{lbmol} / \mathrm{hr})$

$\bar{F}_{\mathrm{B}}=$ nominal value of the total flow rate of reactant B (lbmol/ $\mathrm{hr}$ )

$F_{\mathrm{B} \text {,in }}=$ reactor inlet flow rate of reactant $\mathrm{B}(\mathrm{lbmol} / \mathrm{hr})$

$\bar{F}_{\mathrm{B} \text {,in }}=$ nominal value of the total reactor inlet flow rate of reactant $\mathrm{B}(\mathrm{lbmol} / \mathrm{hr})$

$F_{\mathrm{B} 0}=$ fresh feed flow rate of component $\mathrm{B}(\mathrm{lbmol} / \mathrm{hr})$

$F_{\mathrm{C}}=$ total flow rate of reactant $\mathrm{C}(\mathrm{lbmol} / \mathrm{hr})$

$G_{\mathrm{R} 11}-G_{\mathrm{R} 32}=$ the transfer functions of the reactor

$G_{\mathrm{P} 11}-G_{\mathrm{P} 32}=$ the transfer functions of the process

$k=$ reaction rate constant $(1 / \mathrm{hr})$

$R=$ reaction rate $(\mathrm{mol} / \mathrm{hr})$

$R_{i}=$ reflux flow rate in column $i(\mathrm{lbmol} / \mathrm{hr})$

$V_{i}=$ vapor boilup in column $i(\mathrm{lbmol} / \mathrm{hr})$

$V_{\mathrm{R}}=$ reactor holdup (lbmol)

$x=$ conversion of component $\mathrm{A}$

$x_{B i, j}=$ bottoms composition in the $i$ th column

$x_{D i, j}=$ distillate composition in the $i$ th column

$z_{j}=$ reactor composition of component $j$

$\alpha_{j}=$ relative volatility of component $j$

$\tau_{\mathrm{I}}=$ reset time $(\mathrm{hr})$

$\lambda=$ distribution of reactants $\left(z_{\mathrm{B}} / z_{\mathrm{A}}\right)$

\section{Literature Cited}

(1) Denn, M. M.; Lavie, R. Dynamics of Plants with Recycle. Chem. Eng. J. 1982, 24, 55.

(2) Luyben, W. L. Dynamics and Control of Recycle Systems. 1. Simple Open-Loop and Closed-Loop Systems. Ind. Eng. Chem. Res. 1993, 32, 466.
(3) Luyben, W. L. Dynamics and Control of Recycle Systems. 2. Comparison of Alternative Process Designs. Ind. Eng. Chem. Res. 1993 32,476 .

(4) Morud, J.; Skogestad, S. Dynamic Behavior of Integrated Plants. J. Process Control 1996, 6, 145.

(5) Scali, C.; Ferrari, F. Performance of Control Systems Based on Recycle Compensators in Integrated Plants. J. Process Control 1999, 9, 425 .

(6) Luyben, W. L. Snowball Effect in Reactor/Separator Process with Recycle. Ind. Eng. Chem. Res. 1994, 33, 299.

(7) Papadourakis, A.; Doherty, M. F.; Douglas, J. M. Relative Gain Array for Units in Plants with Recycle. Ind. Eng. Chem. Res. 1987, 26, 1259.

(8) Wu, K. L.; Yu, C. C. Reactor/Separator Processes with Recycle. 1. Candidate Control Structure for Operability. Comput. Chem. Eng. 1996, 20, 1291.

(9) Wu, K. L.; Yu, C. C.; Luyben, W. L.; Skogestad, S. Reactor/ Separator Processes with Recycle. 2. Design for Composition Control. Comput. Chem. Eng. 2002, 27, 421.

(10) Gilliland, E. R.; Gould, L. A.; Boyle, T. J. Dynamic Effects of Material Recycle. Proc. Jt. Autom. Control Conf. 1964, 140.

(11) Verykios, X. E.; Luyben, W. L. Steady-State Sensitivity and Dynamics of a Reactor/Distillation Column Systems with Recycle. ISA Trans. 1978, 17 (2), 31

(12) Taiwo, O. The Design of Robust Control Systems for Plants with Recycle. Int. J. Control 1986, 43, 671.

(13) Zheng, A.; Mahajanam, R. V. A quantitative controllability index and its applications. Ind. Eng. Chem. Res. 1999, 38, 999.

(14) Chodavarapu, S. K.; Zheng; A. Control system design for recycle systems. J. Process Control 2001, 11, 459.

(15) Luyben, W. L. Temperature Control of Autorefrigerated Reactors. J. Process Control 1999, 9, 301.

(16) Lakshminarayanan, S.; Takada, H. Empirical Modeling of Processes with Recycle: Some Insights via Case Studies. Chem. Eng. Sci. 2001, 56 , 3327.

(17) Kwok, K. E.; Chong-Ping, M.; Dumont, G. A. Seasonal Model Based Control of Processes with Recycle Dynamics. Ind. Eng. Chem. Res. 2001, 40, 1633 .

(18) Chen, Y. H.; Yu, C. C. Dynamical Properties of Product Life Cycle: Implications to the Design and Operation of Industrial Processes. Ind. Eng. Chem. Res. 2001, 40, 2452.

(19) Bildea, C. S.; Dimian, A. C.; Iedema, P. D. Nonlinear Behavior of Reactor-Separator-Recycle Systems. Comput. Chem. Eng. 2000, 23, 209.

(20) Pushpavanam, S.; Kienle, A. Nonlinear Behavior of An Ideal Reactor Separator Network with Mass Recycle. Chem. Eng. Sci. 2001, 56, 2837.

(21) Balasubramanian, P.; Kosuri, M. R.; Pushpavanam, S.; Kienle, A. Effect of Delay on the Stability of a Coupled Reactor-Separator System. Ind. Eng. Chem. Res. 2003, 42, 3758.

(22) Kiss, A. A.; Bildea, C. S.; Dimian, A. C.; Iedema, P. D. State Multiplicity in CSTR-Separator-Recycle Polymerisation Systems. Chem. Eng. Sci. 2002, 57, 535.

(23) Bildea, C. S.; Dimian, A. C. Fixing Flow Rates in Recycle Systems: Luyben's Rule Revisited. Ind. Eng. Chem. Res. 2003, 42, 4578.

(24) Murthy Konda, N. V. S. N.; Rangaiah, G. P.; Krishnaswamy, P. R. Plantwide Control of Industrial Processes: An Integrated Framework of Simulation and Hueristics. Ind. Eng. Chem. Res. 2005, 44, 8300.

(25) Cheng, Y. C.; Yu, C. C. Effects of Design on Recycle Dynamics and Implications on Control Structure Selection, Ind. Eng. Chem. Res. 2003 $42,4348$.

(26) Gadewar, S. B.; Doherty, M. F.; Malone, M. F. Reaction Invariants and Balances for Plant Complexes. Ind. Eng. Chem. Res. 2002, 41, 3771.

(27) Cheng, Y. C.; Yu, C. C. Optimal Region for Design and Control of Ternary Systems with Two Recycle Systems. AIChE J. 2003, 49, 682

(28) Douglas, J. M. Conceptual Design of Chemical Processes; McGrawHill: New York, 1988.

(29) Shen, S. H.; Yu, C. C. Use of Relay-Feedback Test for Automatic Tuning of Multivariable Systems. AIChE J. 1994, 40, 627.

(30) Seborg, D. E.; Edgar, T. F.; Mellichamp, D. A. Process Dynamics and Control, 2nd ed.; Wiley: New York, 2004.

Received for review December 29, 2005 Revised manuscript received August 13, 2006 Accepted August 24, 2006

IE051449+ 